\title{
Development and characterization of a single particle laser ablation mass spectrometer (SPLAM) for organic aerosol studies
}

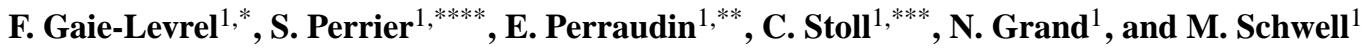 \\ ${ }^{1}$ Laboratoire Interuniversitaire des Systèmes Atmosphériques (LISA), UMR7583, CNRS - Université Paris Est Créteil and \\ Université Paris Diderot, Institut Pierre Simon Laplace, 61 Avenue du Général de Gaulle, 94010 Créteil, France \\ * now at: Synchrotron Soleil, L'Orme des Merisiers, St. Aubin, B.P. 48, 91192 Gif-sur-Yvette Cédex, France \\ ** now at: Univ. Bordeaux, EPOC, UMR5805, 33400 Talence, France \\ *** now at: Leibniz Universität Hannover, Institut für Mehrphasenprozesse, 30167 Hannover, Germany \\ ${ }^{* * * * *}$ now at: Université de Lyon 1, Institut des Sciences Analytiques, UMR5280 - CNRS, ENS-Lyon, 5 rue de la Doua, 69100 \\ Villeurbanne, France
}

Correspondence to: F. Gaie-Levrel (francois.gaie-levrel@synchrotron-soleil.fr) and

M. Schwell (martin.schwell@ lisa.u-pec.fr)

Received: 22 June 2011 - Published in Atmos. Meas. Tech. Discuss.: 4 July 2011

Revised: 23 December 2011 - Accepted: 18 January 2012 - Published: 26 January 2012

\begin{abstract}
A single particle instrument was developed for real-time analysis of organic aerosol. This instrument, named Single Particle Laser Ablation Mass Spectrometry (SPLAM), samples particles using an aerodynamic lens system for which the theoretical performances were calculated. At the outlet of this system, particle detection and sizing are realized by using two continuous diode lasers operating at $\lambda=403 \mathrm{~nm}$. Polystyrene Latex (PSL), sodium chloride $(\mathrm{NaCl})$ and dioctylphtalate $(\mathrm{DOP})$ particles were used to characterize and calibrate optical detection of SPLAM. The optical detection limit (DL) and detection efficiency (DE) were determined using size-selected DOP particles. The DE ranges from 0.1 to $90 \%$ for 100 and $350 \mathrm{~nm}$ DOP particles respectively and the SPLAM instrument is able to detect and size-resolve particles as small as $110-120 \mathrm{~nm}$. During optical detection, particle scattered light from the two diode lasers, is detected by two photomultipliers and the detected signals are used to trigger UV excimer laser $(\lambda=248 \mathrm{~nm})$ used for one-step laser desorption ionization (LDI) of individual aerosol particles. The formed ions are analyzed by a $1 \mathrm{~m}$ linear time-of-flight mass spectrometer in order to access to the chemical composition of individual particles. The TOF-MS detection limit for gaseous aromatic compounds was determined to be $0.85 \times 10^{-15} \mathrm{~kg}\left(\sim 4 \times 10^{3}\right.$ molecules $)$. DOP particles were also used to test the overall operation of the instrument. The analysis of a secondary organic aerosol, formed in a smog chamber by the ozonolysis of indene, is presented as a first application of the instrument. Single particle mass spectra were obtained with an effective hit rate of $8 \%$. Some of
\end{abstract}

these mass spectra were found to be very different from one particle to another possibly reflecting chemical differences within the investigated indene SOA particles. Our study shows that an exhaustive statistical analysis, over hundreds of particles, and adapted reference mass spectra are further needed to understand the chemical meaning of single particle mass spectra of chemically complex submicrometer-sized organic aerosols.

\section{Introduction}

Atmospheric aerosols are known to have a large impact on human health (Vedal et al., 2006), atmospheric chemistry and climate (IPCC, 2007). These effects, which depend strongly on the aerosol chemical composition, are still poorly understood. This is partly due to the incomplete characterization of the aerosol chemical composition and in particular its organic fraction (Kanakidou et al., 2005; Hallquist et al., 2009).

Organic aerosols (OA) can be separated into primary organic aerosols (POA), directly emitted in the atmosphere, and secondary organic aerosols (SOA), formed by gas-to-particle conversion after atmospheric oxidation of anthropogenic and biogenic volatile organic compounds (VOC). Due to the large number of implicated molecules and to the diversity of their chemical functionalities and physico-chemical properties, the chemical composition of the organic fraction is complex. Moreover, complex processes such as SOA formation, cloud-aerosol interactions 
and atmospheric ageing remain poorly understood, partly because of the difficulty to describe the organic aerosol composition. OA are indeed composed of a complex mixture of compounds with a wide range of polarity, functional groups, molecular weight... and present at trace levels).

In this context, two main types of methods were adapted or developed to analyze OA and improve our knowledge of its composition and evolution. On one hand, off-line analytical techniques are used to elucidate these processes down to the molecular level. However, due to the complexity of the aerosol chemical composition, only a reduced fraction (up to $30 \%$ ) of the collected and extracted mass can be identified on a molecular level (Cocker et al., 2001; Chiappini et al., 2006; Hamilton et al., 2008; Gómez-González et al., 2008). Furthermore, these techniques are limited by a low temporal resolution because of the time needed to collect a sufficient amount of sample for the analysis. On the other hand, real-time techniques (temporal resolution $<1 \mathrm{~min}$ ), such as aerosol mass spectrometers (Sullivan and Prather, 2005), are also used to get a better understanding of the chemical processes, such as, for example SOA formation (Bahreini et al., 2005; Alfarra et al., 2006).

The ideal instrument as proposed by Jimenez et al. (2004) would meet all these requirements and allow for both a high temporal resolution and an access to the chemical speciation at the molecular level for each individual sampled particle. Due to their operating principle, aerosol mass spectrometers seem well suited to access to such analysis. They are generally composed by three operating parts: (1) - a particle sampling interface, (2) - an optical detection/sizing device, and (3) - a mass spectrometer.

A large number of techniques have been implemented in the development of aerosol mass spectrometers capable of determining the size, the morphology, the optical properties, or the elemental and molecular composition of particle in real time. Davis (1973) was the first to develop a thermal desorption aerosol mass spectrometer. In this instrument, aerosols are sampled through a steel capillary, impacted on a heated surface (up to $1700^{\circ} \mathrm{C}$ ) and are flash-evaporated as an ionized gas that is then analyzed by a magnetic sector analyzer. Other surface ionization instruments were developed using quadrupole mass spectrometers (Lassiter and Moen, 1974; Myers and Fite, 1975) which are only capable of studying one $m / z$ at a time. During the 1980's, this one-step vaporization/ionization technique has evolved to become a two-step technique by coupling a flash vaporization, at lower temperatures, to an electron impact ionization of the vaporized species (Allen and Gould, 1981; Sinha et al., 1982). Nowadays, the commercially available Aerodyne Aerosol Mass Spectrometer (AMS) still uses this scheme (Jayne et al., 2000; Drewnick et al., 2005; Canagaratna et al., 2007). In the same way, Tobias and Ziemann (1999) used a Temperature-Programmed Thermal Desorption Particle Beam Mass Spectrometry (TDPBMS) to achieve successive vaporization of components according to their vapor pressures such as for SOA formed in a smog chamber (Tobias et al., 2000). Thereafter, Atmospheric Pressure Chemical Ionization Mass Spectrometry (APCI-MS) (Hoffmann et al., 2002) has been used as a soft ionization technique.

Knowing that thermal desorption allows analyzing many particles simultaneously, the development of laser aerosol mass spectrometry techniques was an opportunity to obtain single particle information in real time (Prather et al., 1994; Weiss et al., 1997). Aerosols, focused into the mass spectrometer for example by an aerodynamic lens system (ALS), are detected by one or two continuous wave (cw) lasers. They are perpendicularly aligned to the particle beam and are mostly operated in the visible spectral range. In the case of two laser beams, particles can be aerodynamically sized by measuring their transit time between both laser beams. The measured particle velocity can then be used easily to calculate the necessary time delay to trigger a pulsed laser (IR or UV) for individual particle desorption and ionization. The formed ions are then detected by a mass spectrometer. This kind of technique is able to give physical and chemical properties of individual particles in real time. It was firstly introduced by Sinha (1984), who used Nd:YAG laser pulses at $266 \mathrm{~nm}$ for the particle desorption/ionization in one step (LDI) and a quadrupole mass spectrometer for the chemical analysis. Other laser-based single particle mass spectrometers were developed later (Hinz et al., 1994; Prather et al., 1994; Nordmeyer and Prather, 1994; Noble et al., 1994; Weiss et al., 1997). Please note that LDI refers in this paper exclusively to one-step laser desorption/ionization process.

The real power of this technique came up by combining LDI with Time-of-Flight mass spectrometry (TOF-MS) for the ion analysis (McKeown et al., 1991). Because of its pulsed mode operation, TOF-MS is ideally suited to be linked to a pulsed desorption/ionization method. Note that only the power density (in $\mathrm{W} \mathrm{m}^{-2}$ ) of a nanosecond laser pulse is high enough to provide a substantial and rapid desorption of molecules from the particulate phase. Other advantages of TOF-MS are (i) its ability to obtain an entire mass spectrum on the order of microseconds, (ii) the theoretical unlimited mass range and (iii) its ion transmission efficiency close to $100 \%$ and independent of $\mathrm{m} / \mathrm{z}$ ratio. Several groups designed such single particle instruments which have been used to address a large variety of scientific cases (Hinz et al., 1994; Murphy and Thomson, 1995; Carson et al., 1995; Reents et al., 1995; Noble and Prather, 1996; Weiss et al., 1997; Gard et al., 1997; Murphy et al., 1998; Woods et al., 2001; Hunt and Petrucci, 2002). Besides the simultaneous sizing and chemical composition analysis, real time single particle techniques are able to provide information for each sampled particle.

One short-coming of the LDI technique is the fragmentation of organic molecules since the number of photons absorbed by a specific molecule during the LDI 
process cannot be efficiently controlled and thus dissociative ionization is not avoidable. Molecular speciation is difficult to achieve in these conditions. However, we note that interesting results relevant for the investigation of $\mathrm{OA}$ chemistry, as for example the identification of oligomeric species or the chemical characterization of different types of SOA, can nevertheless be obtained with a LDI instrument (Gross et al., 2006; Huang et al., 2007).

One way to overcome the fragmentation problem is to use a Two-Step Laser Desorption/Ionization (L2DI) where vaporization and ionization are separated in time by a few microseconds. The first vaporization step can be achieved without ionizing the parent molecules which permits the reduction of the UV laser power density for the second step in order to ionize molecular species near their ionization thresholds by, for example, Resonant-Two Photon Ionization (R2PI) or Single Photon Ionization (SPI) with VUV laser radiation or synchrotron radiation. Single particle L2DI was investigated by the T. Baer and K. Prather groups in the late 1990's and early 2000's who successfully studied micrometer sized droplets consisting of pure substances (Morrical et al., 1998; Cabalo et al., 2000; Woods et al., 2001; Smith et al., 2002). Single-particle L2DI was also used successfully to identify molecular tracers of different types of real-world traffic-related and wood combustion aerosols such as polycyclic aromatic hydrocarbons (Lazar et al., 1999; Bente et al., 2008, 2009). These results have shown that single particle L2DI allows fragment-free mass spectra to be obtained. However, it is still a real analytical challenge to adapt and apply this technique for an exhaustive investigation of the chemical analysis of OA particles containing a complex mixture of species that easily undergo dissociative ionization.

In this paper, we present a newly built real-time single-particle aerosol mass spectrometer, named "SPLAM" for Single-Particle Laser Ablation Mass Spectrometry. This one step LDI-based instrument has been developed in our laboratory to sample, detect, determine the size and analyze organic single particle in real time. The development and characterization of the ALS, the optical detection system, the TOF-MS, and the triggering process are outlined. As a first application, we present results obtained for the analysis of a SOA produced in the laboratory from the ozonolysis of indene in the CESAM simulation chamber at LISA (Wang et al., 2011).

\section{System design}

The SPLAM instrument is composed of three main parts (Fig. 1): (1) an aerodynamic focusing lens system to sample and introduce particles into the vacuum system by forming a beam of very low divergence, and two differentially pumping stages; (2) the optical detection/aerodynamic particle sizing device which permits the determination of

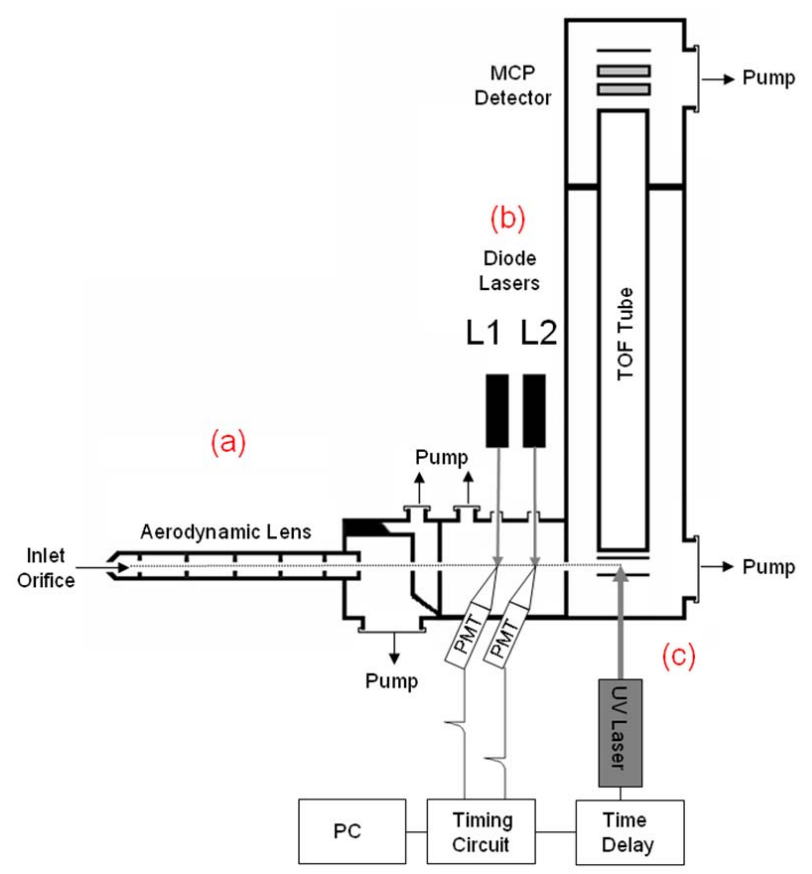

Fig. 1. Schematic illustration of the Single Particle Laser Ablation Mass Spectrometry (SPLAM) instrument: (a) particles are focused by an aerodynamic lens system, (b) the particle beam crosses two continuous diode laser beams allowing optical detection of individual particles and determination of their respective aerodynamic diameter, (c) an external timing circuit permits to trigger a UV laser to vaporize and ionize individual particles. The formed ions are analyzed by the time-of-flight mass spectrometer.

the aerodynamic diameter of the detected particles and the synchronization with the third part of the instrument and; (3) the chemical characterization region which consists of a vaporization/ionization region and a linear time-of-flight mass spectrometer with $1 \mathrm{~m}$ field free drift region. The TOF-MS with its aerosol inlet is mounted on a scientific table with rolls ("W" $\times$ "L" $=0.6 \times 1 \mathrm{~m}$; "H" (including TOF tube) $=2.5 \mathrm{~m}$ ) and can be moved easily. This table is mechanically separated from the laser sources of SPLAM which are all placed on an additional $1.2 \times 2.2 \mathrm{~m}$ optical table (Newport). The present configuration is suitable for laboratory use only and cannot be operated in its present state for field measurements. Each part of the instrument is presented in the next sections.

\subsection{The aerodynamic lens system}

Aerosol mass spectrometry relies on the capability to bring particles into a high vacuum system and to focus them spatially into the ion source of a mass spectrometer. For this purpose, the aerodynamic lens system developed initially in Peter McMurry's group (Liu et al., 1995a, b) has been widely used by many groups and for many different applications. Concerning the SPLAM instrument, 
a new ALS was designed using the theoretical model and operational software described by Wang et al. (2005a, b and 2006). The following criteria have been considered: (1) transmission of a broad diameter range (100 to $2000 \mathrm{~nm}$ ) corresponding to the size range of atmospheric aerosol containing the highest organic fraction (Zhang et al., 2007), (2) good transmission efficiency with low beam divergence, and (3) acceleration of particles to a speed which is characteristic of their diameters (100 to $150 \mathrm{~m} \mathrm{~s}^{-1}$ ).

Our lens system has been exactly machined according to the dimensions calculated by Wang's design tool $(1 / 10 \mathrm{~mm}$ precision for orifices, $1 / 100 \mathrm{~mm}$ precision for the alignment). A technical drawing is presented in Fig. 2. Our ALS is composed of five orifices mounted in a precision stainless steel tube and starting from $6.93 \mathrm{~mm}$ at the inlet and gradually decreasing to $3.11 \mathrm{~mm}$ at the exit, all separated by $90 \mathrm{~mm}$ spacers. Note that these orifices can be exchanged if different lens properties are to be obtained. Aerosol flow enters the instrument through a $100 \mu \mathrm{m}$ critical orifice (Microcontrole) into the aerodynamic lens. The volume flowrate has been measured to be $0.0831 \mathrm{~min}^{-1}$, which is in good agreement with the model calculations. Downstream this orifice, a relaxation chamber limits the perturbations caused by the sampling process. The first four lenses focus the particles on a centre line and the final exit aperture the accelerating nozzle - controls gas expansion and particle acceleration in the vacuum system. This $7 \mathrm{~mm}$ diameter final nozzle plays an important role for the particle beam diameter determination (Liu et al., 1995a, b). The outlet of the lens system is located in the first vacuum chamber where a $2501 \mathrm{~s}^{-1}$ turbomolecular pump (Varian, model V301) is used to maintain a pressure of $10^{-3} \mathrm{mbar}$ when the lens inlet is open $\left(10^{-7}\right.$ mbar with closed ALS).

Wang's design tool (Wang et al., 2006) also allows modeling the theoretical performances for an ALS of given dimensions. For our system, a theoretical transmission efficiency of $100 \%$ was calculated for particle diameters ranging from $200 \mathrm{~nm}$ to $4 \mu \mathrm{m}$ and more than $90 \%$ for particles diameter larger than $30 \mathrm{~nm}$. At the ion source of the TOF-MS ( $20 \mathrm{~cm}$ downstream the accelerating nozzle), the theoretical particle beam diameter was calculated to be smaller than $1 \mathrm{~mm}$.

The ALS is fixed and can only be moved in the particle beam direction. The focused particles continue to travel along a straight-line path towards the detection/sizing chamber by passing successively through two pinholes separated by $2 \mathrm{~cm}$. This constitutes the next step of differential pumping. The space in-between is evacuated by a $681 \mathrm{~s}^{-1}$ turbomolecular pump (Varian, model V70) maintaining a pressure of $10^{-4}$ mbar when the ALS is open. The pinholes have respectively inner diameters of 1.5 and $1 \mathrm{~mm}$ and lengths of 5 and $23 \mathrm{~mm}$.

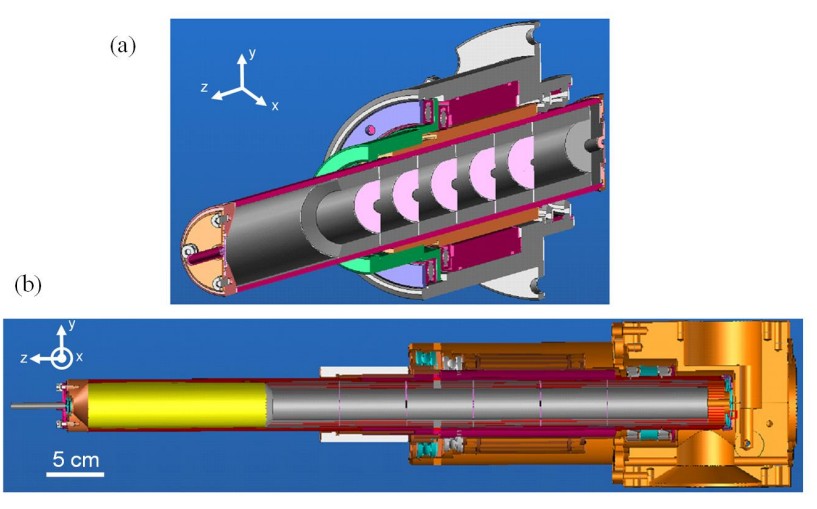

Fig. 2. Scheme of the aerodynamic lens system of SPLAM and its $z$-translation mechanism (vertical cuts). (a) View of the five lens orifices and the relaxation chamber. (b) View of the ALS integrated into the first two pumping stage regions (drawings: Mecaconcept).

\subsection{The optical detection/aerodynamic particle sizing region}

The real-time sizing of a particle and the synchronization between its detection and its ionization and mass analysis remains a major challenge in aerosol mass spectrometry. One way to provide improved size information is to use a two-laser particle velocity measurement as implemented in the SPLAM instrument.

\subsubsection{Description of the optical detection}

After exiting the first two differential pumping stages, particles enter the optical detection/sizing region $\left(P=10^{-5} \mathrm{mbar}\right.$ when ALS inlet is open) where they pass through two continuous wave (cw) diode laser beams emitting light at $\lambda=403 \mathrm{~nm}$ (Coherent Radius, $P \approx 40 \mathrm{~mW}$ ). This wavelength has been chosen in order to enhance the detection efficiency for particles of $d<500 \mathrm{~nm}$. At the same time, being at the edge of the visible spectral range, the violet light still permits a relatively easy alignment of the two lasers.

These $\mathrm{cw}$ laser beams are spaced by $41 \pm 0.5 \mathrm{~mm}$ and respectively called L1 and L2 (Figs. 1 and 3). This distance was imposed by the optomechanical elements used for laser beam introduction in the detection chamber: Microbench elements (Linos), integrating a glass window, are fixed directly to the detection chamber (not shown in Fig. 3). The two lasers themselves are placed outside the vacuum system on the $1.2 \times 2.2 \mathrm{~m}$ optical table where an optical spatial filter and a beam collimation system limit the stray light and optimize the intersection of the particle and the laser beam (not shown). The Gaussian shaped cross sections of the laser beam were determined experimentally at the intersection zone using a CCD camera (Gentec, "Beam'R"). The measures of the laser beam diameters are 315.5 and $334.8 \mu \mathrm{m}$ at $1 / e^{2}$ and 760.9 and $755.4 \mu \mathrm{m}$ at 


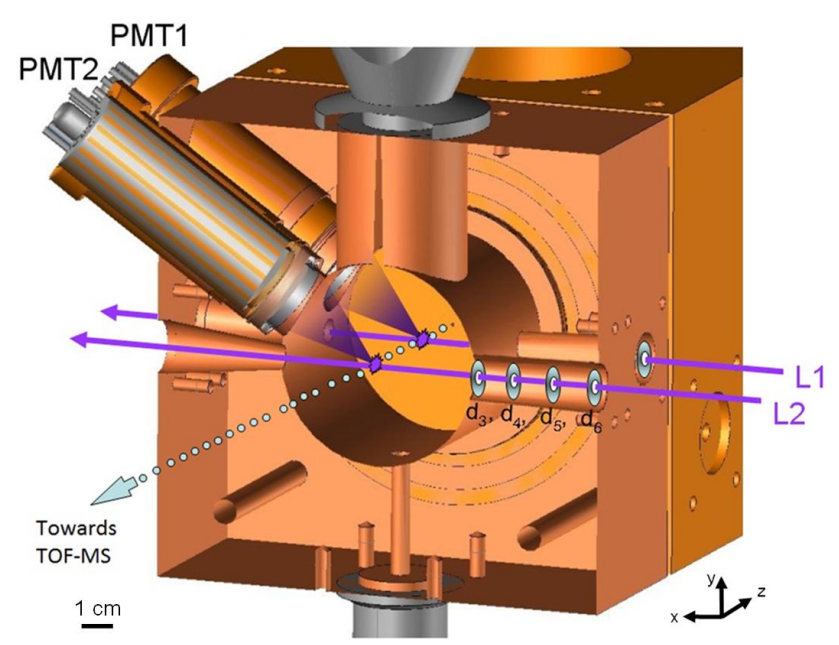

Fig. 3. Optical detection chamber of SPLAM. The particle beam crosses two diode laser beams (L1 \& L2). Particle scattered light is detected in forward direction by two photomultiplier tubes at an angle of $34 \pm 13^{\circ}$ (centre of active detection area, see Sect. 2.2). The four diaphragms inserted into the tunnels of the incoming laser light avoid the penetration of reflected light from the entrance windows (not shown) into the detection chamber. The laser beams are trapped by light horns (not shown).

$1.5 \%$ of maximum intensity for $\mathrm{L} 1$ and $\mathrm{L} 2$ respectively with experimental powers of $P_{\mathrm{L} 1}=41.3 \mathrm{~mW}$ and $P_{\mathrm{L} 2}=31.2 \mathrm{~mW}$.

Figure 3 is a technical drawing presenting the optical detection chamber of the SPLAM instrument. According to Mie theory, the maximum of particle scattered light is in the forward direction and independent of wavelength. In this way, the two photomultiplier tubes (PMT, Photonis, model XP2930), used for the detection of particle scattered light, were placed at an angle of $34^{\circ}$ with respect to the forward direction of the laser beams. As can be seen in Fig. 3, mechanical constraints do not permit to set the PMT even closer to the laser beam in our configuration since the PMT have circular active areas of $\emptyset=23 \mathrm{~mm}$ and are placed at $37 \mathrm{~mm}$ distance only from the particle/laser intersection zone, in order to cover a maximum solid angle.

The PMTs are separated by glass windows from the vacuum chamber. In order to limit the stray light inside the particle detection chamber, and thus the noise on the PMT, the internal walls were completely blackened and two sets of four diaphragms were inserted inside of both laser inlets (Fig. 3) which efficiently avoid penetration of reflected light from the entrance windows. Finally, two specially machined light horns are used to trap the photons at both laser exits (not shown in Fig. 3).

\subsubsection{Aerodynamic particle sizing: description and calibration}

When particles pass through the first laser beam, the scattered light is detected by the first PMT which triggers an external timing circuit which has been programmed on a field programmable gate array (FPGA, see Sect. 2.4). The passage in the second laser beam allows for particle velocity determination by measuring the transit time $\left(t_{\mathrm{opt}}\right)$ of the particle between the two laser beams for the given beam separation distance $(41 \pm 0.5 \mathrm{~mm})$. Vacuum aerodynamic diameters $\left(d_{\mathrm{aev}}\right)$, defined as the diameter of a sphere with standard density which has the same terminal velocity as the particle of interest (DeCarlo et al., 2004), are then derived for three types of size selected aerosols, as shown in Fig. 4. This figure shows experimental calibration curves for aerodynamic particle sizing measurements performed with four certified sizes of PolyStyrene Latex (PSL, Duke Scientific Corp.), and selected DioctylPhthalate (DOP) and sodium chloride $(\mathrm{NaCl})$ particle diameters using a differential mobility analyzer (DMA, model 3080L, TSI inc.). These particles were produced using an atomizer (model 3076, TSI inc.) and a diffusion dryer (model 3062,TSI inc.) to remove water in the case of PSL and $\mathrm{NaCl}$ particle generation. Each point represents the average of hundred detected particles and horizontal error bars correspond to an error propagation of $95 \%$ confidence intervals. In order to avoid the detection of two or more particles at the same time during these experiments, the number concentration of the aerosol to be characterized is limited on purpose. The upper limit of particle concentration can be estimated by taking into account a typical particle velocity of $100 \mathrm{~m} \mathrm{~s}^{-1}$ whose transit time $t_{\mathrm{opt}}$ between the two lasers would be about $400 \mu$ s. Given the experimental volumetric flowrate of $0.0831 \mathrm{~min}^{-1}$, this yields a maximum number concentration of about $1.7 \times 10^{3}$ particles $\mathrm{cm}^{-3}$ that should not be exceeded for $d_{\mathrm{aev}}$ measurements with the SPLAM optical detection. Therefore, in order to avoid coincidence events during optical detection process, one or two dilution systems were used (1/100 diluters, model DIL-550, Topas GmbH) especially in the case of the production of particles using the atomizer.

Using counting of size-selected DOP particles, the calibration measurements provided a detection limit of $d_{\mathrm{aev}}=100-110 \mathrm{~nm}$ (see Sect. 2.2.3) which is probably optical and not caused by the transmission efficiency of the aerodynamic lens system, according to the previous ALS theoretical characterization (Sect. 2.1). The particle velocity variability observed for the smaller aerodynamic diameters can be explained by the fact that small particles have more divergent flight paths inside the particle beam. This leads to more spread positions of smaller particles inside the cw laser beams, and consequently to a broader scattered light intensity range. 

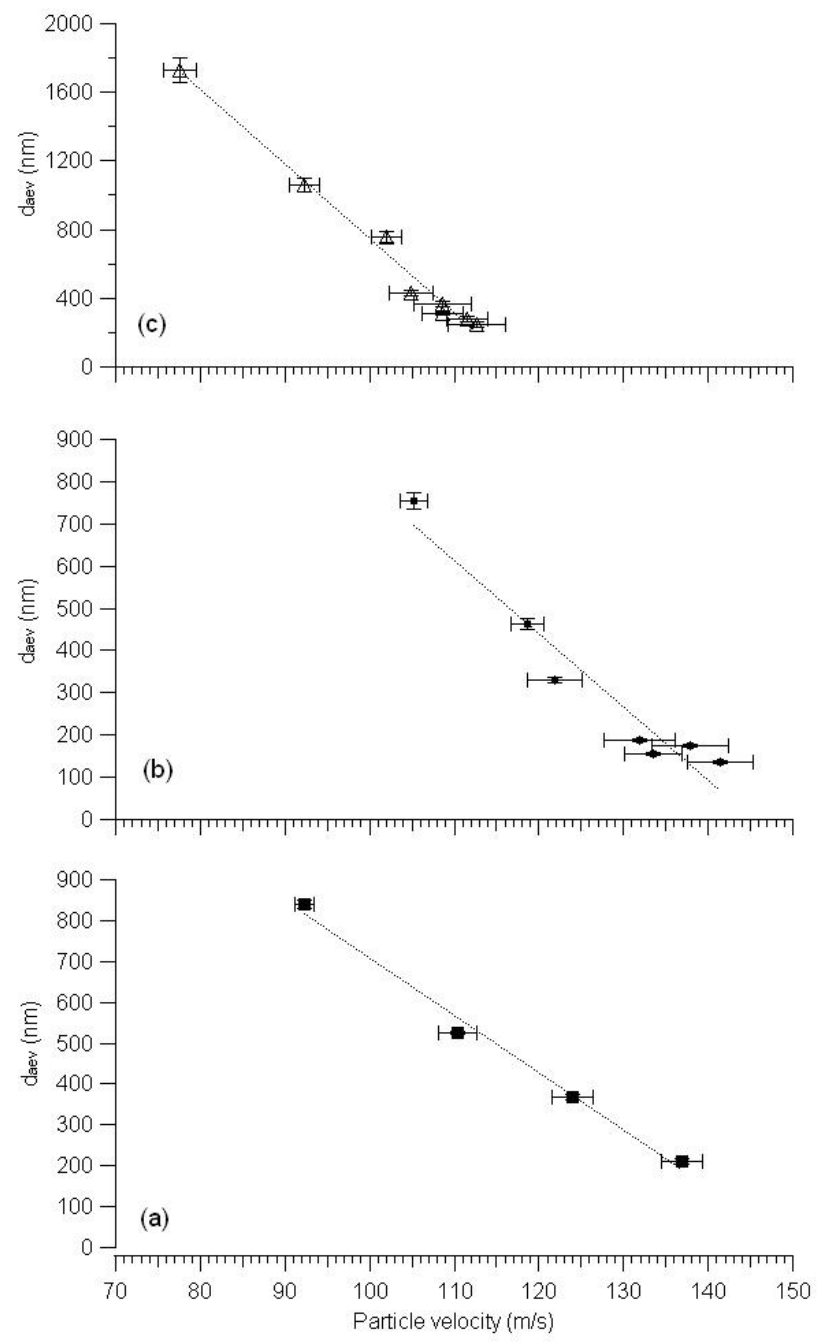

Fig. 4. Experimental calibration curves for aerodynamic particle sizing of the SPLAM instrument obtained for (a) - PSL, (b) DOP and (c) $-\mathrm{NaCl}$ particles. The dash lines correspond to linear guideline.

\subsubsection{Optical detection efficiency and aerodynamic particle sizing performances comparison}

Figure 5a compares the optical detection efficiency (DE) of SPLAM (black circles) to the above cited single particle instruments as a function of vacuum aerodynamic diameter (see Sect. 1). The SPLAM DE was calculated as the ratio between the count rate of DOP particles measured with PMT2 (L2 scattered light, Fig. 3) and the one obtained with a condensation particle counter (CPC, model 3010, TSI inc.) connected in parallel to the ALS. Note that the PMT1 count rate (L1 scattered light, Fig. 3) is higher, however we plot L2 DE since only two-fold detection permits velocity determination and triggering of the pulsed LDI laser. This means that SPLAM DE takes into account the number of particles that cross both laser beams L1 and L2 since

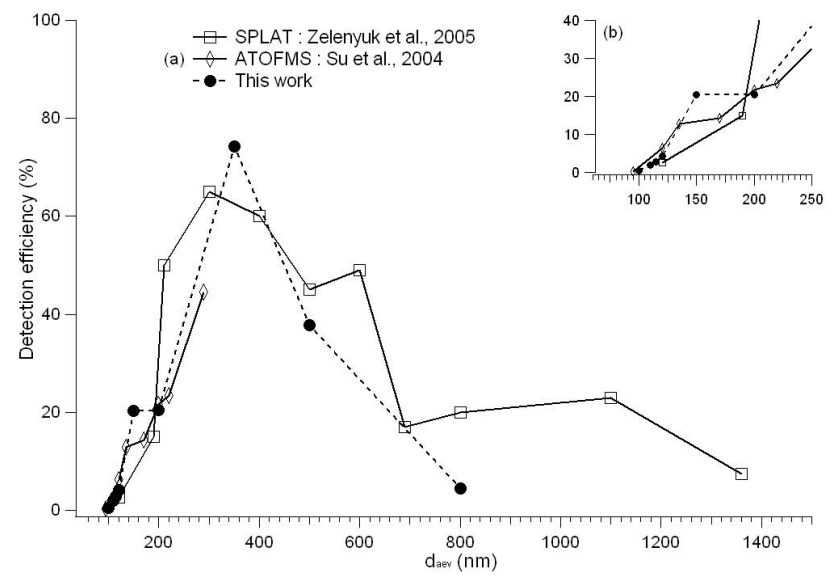

Fig. 5. (a) DOP particles detection efficiency for SPLAM instrument (black circles) and PSL particles detection efficiency for SPLAT (Zelenyuk et al., 2005) (open squares) and ATOFMS (Su et al., 2004) (open diamond) instruments plotted as a function of vacuum aerodynamic diameter, (b) close up of the graph (a) between 50 and $250 \mathrm{~nm}$.

detection in L2 position necessarily implies a detection in L1. Different reasons may explain the observed higher L1 count rate (for example different laser power) and will not be discussed here. Our DE is given for DOP particles whereas the SPLAT (Zelenyuk et al., 2005) (open squares) and ATOFMS (Su et al., 2004) (open diamonds) DEs are given for PSL particles.

A close-up of panel a from 50 to $250 \mathrm{~nm}$ is shown in panel $b$. From panel $b$, the optical detection limit of SPLAM can be estimated to be at about $100 \mathrm{~nm}$ particle aerodynamic diameter $(\mathrm{DE}=0.4 \%)$. As expected, close to the detection limit, the DE is relatively poor (below $5 \%$ ). However, it increases rapidly for bigger particles reaching a maximum of $74 \%$ at $350 \mathrm{~nm}$.

The SPLAT and ATOFMS DEs are very similar to those obtained for SPLAM, although in these two instruments elliptical mirrors for the collection of scattered photons are implemented in order to enhance their DEs. One way to understand the similar DEs obtained for fine particles despite fairly different optical setups is to consider the differences in the $\mathrm{cw}$ laser wavelengths used. In fact, the ATOFMS and SPLAT both operate with green $\mathrm{cw}$ lasers $(\lambda=532 \mathrm{~nm})$ whereas the violet laser implemented inside SPLAM favors the detection of fine and ultrafine particles according to Mie theory. However, the decrease towards the $1 \mu \mathrm{m}$ is somewhat more pronounced in our instrument as compared to SPLAT which could also be a difference due to different wavelengths used. 


\subsection{Chemical characterization region: the photoionization time-of-flight mass spectrometer}

After being detected and sized, the particles enter the ionization source of the mass spectrometer where short-lived burst of ions are produced. Time-of-flight mass analyzers are ideally suited for characterizing simultaneously all the ions formed during the LDI process for each detected particle.

An home-made TOF mass spectrometer was implemented in the SPLAM instrument. After passing through a $1 \mathrm{~mm}$ orifice with a length of $5 \mathrm{~mm}$, the particles reach the TOF-MS ionization region where a pressure of $10^{-8} \mathrm{mbar}$ is maintained by two $2501 \mathrm{~s}^{-1}$ turbomolecular pumps (Varian V301). The pressure in this region does not change at all when the ALS inlet is opened. This is particularly important since it means that the differential pumping system is very efficient and that the TOF-MS will exclusively detect compounds from the aerosol phase during sampling. This was further evidenced by introducing gaseous toluene via the ALS inlet. R2PI $(\lambda=248 \mathrm{~nm})$ coupled to TOF-MS is extremely sensitive to aromatic hydrocarbons (see also below), however no toluene could be detected under these conditions.

A $17 \mathrm{~mJ}$ excimer laser (KrF, Optex, LambdaPhysik) emitting at $\lambda=248 \mathrm{~nm}$ was used as a desorption/ionization laser at a maximum repetition rate of $10 \mathrm{~Hz}$ and a pulse width of $10 \mathrm{~ns}$. The laser is focused into the ion source by an $f=30 \mathrm{~cm}$ fused silica lens. The ion extraction region of the TOF-MS is slightly off the focal point yielding a $7.5 \times 1 \mathrm{~mm}$ rectangular shaped spot in this region. This spot was horizontally oriented in order to optimize the mass resolution and to maximize the hit efficiency since particles will travel through the longer axis of this rectangle. Here, the laser power density reaches about $1.4 \times 10^{7} \mathrm{~W} \mathrm{~cm}^{-2}$ (at $12 \mathrm{~mJ}$ pulse energy).

The TOF-MS itself is of linear configuration and is operating according to the Wiley-McLaren ion space focusing conditions (Wiley and McLaren, 1955). It has a two-stage accelerating electric field consisting of a three copper plate grids, spaced by $1 \mathrm{~cm}$. The length of the field free drift region is $1 \mathrm{~m}$. A Behlke high voltage switch (HTS 21-06-GSM) is used to extract the ions orthogonally to the particle beam. The Behlke switch has a very steep edge $(<3 \mathrm{~ns})$ and thus favors good mass resolution. Moreover, in order to further improve the mass resolution, a delay time $\tau$ is applied for the ion extraction (see Sect. 2.4) (Wiley and McLaren, 1955). The acceleration potentials used are +145 and $-1460 \mathrm{~V}$ respectively for the extraction and acceleration region. Positive ions are detected by two $40 \mathrm{~mm}$ microchannel plate detectors in series (MCP, Hamamatsu). The signals are preamplified (Ortec fast preamplifier) and sent to an acquisition card (National Instruments, PXI-5621, $64 \mathrm{MHz}, 14$ bit vertical resolution) interfaced to a personal computer. In its latest version, the TOF-MS achieves a mass resolution of $m / \Delta m \approx 500$ (for LDI desorbed DOP molecules).

The sensitivity of the TOF-MS has been characterized using an effusive inlet for gaseous molecules, coupled directly to the ion source chamber. Using the $\mathrm{KrF}$ excimer laser, most of aromatic compounds which have intensive $S_{0} \rightarrow S_{n}$ electronic transitions at $\lambda=248 \mathrm{~nm}$, can be ionized near their ionization threshold with R2PI thus avoiding dissociative ionization. For such compounds, fragment free mass spectra can be obtained. Moreover, under these conditions, molecular oxygen, molecular nitrogen, carbon dioxide, alkanes, alkenes, and aliphatic aldehydes are almost not ionized and thus background noise is significantly reduced (Zimmermann et al., 1997). This allows very low detection limits (DL) for aromatic compounds. A series of semi-volatile polycyclic aromatic hydrocarbons (HC) was studied in gas phase in order to determine the SPLAM molecular DL. Typically, when about 100 mass spectra are averaged, a few hundreds of molecules are needed inside the ionization volume to give an appreciable mass signal. For single shot mass spectra, a few thousand molecules are needed (Gaie-Levrel, 2009). These numbers can be used to estimate the capabilities of SPLAM in the case of aerosol particles. For gaseous 2-methylnaphthalene, for example, the TOF-MS is able to detect $1.6 \times 10^{5}$ molecules in its ionization volume yielding a weight DL of 0.85 attogram (excimer laser power density $\approx 2 \times 10^{6} \mathrm{~W} \mathrm{~cm}^{-2}$ ) by taking into account that a signal is detectable when the signal to noise ratio is higher than 3. Supposing a homogeneous $d=200 \mathrm{~nm}$ particle composed of a $M=150 \mathrm{~g} \mathrm{~mol}^{-1}$ compound and a $1 \mathrm{~g} \mathrm{~cm}^{-3}$ density, a particle weight of $4 \mathrm{fg}$ can be calculated $\left(\sim 2 \times 10^{7}\right.$ molecules). In principle, our TOF-MS has thus the ability to detect 2-methylnaphthalene with a $0.02 \%$ weight fraction inside this particle. However, since the DL is estimated from gas phase R2PI, the estimation for the particle case holds only for complete particle vaporization and for an optimal spatial and time overlap between the ionization volume and the gas plume of the vaporized particle. Furthermore, a higher power density is needed for the LDI process. Hence, R2PI is difficult to achieve in these conditions and the estimation given above is most probably a lower limit for detection limit.

During these gas phase experiments, a series of non-aromatic compounds with relevance for SOA chemistry (terpenes and related atmospheric oxidation products) were also studied. Although the electronic transition moments of this class of compounds are generally not zero at $248 \mathrm{~nm}$, only poor DL were obtained and dissociative ionization was predominant in the mass spectra. We can thus conclude, that SPLAM using $\lambda=248 \mathrm{~nm}$ for Resonance-Enhanced Multiphoton-Ionization (REMPI) will be a method well suited for the detection of particle-bound aromatic molecules, such as for example those found in anthropogenic or biomass burning aerosols. This conclusion 


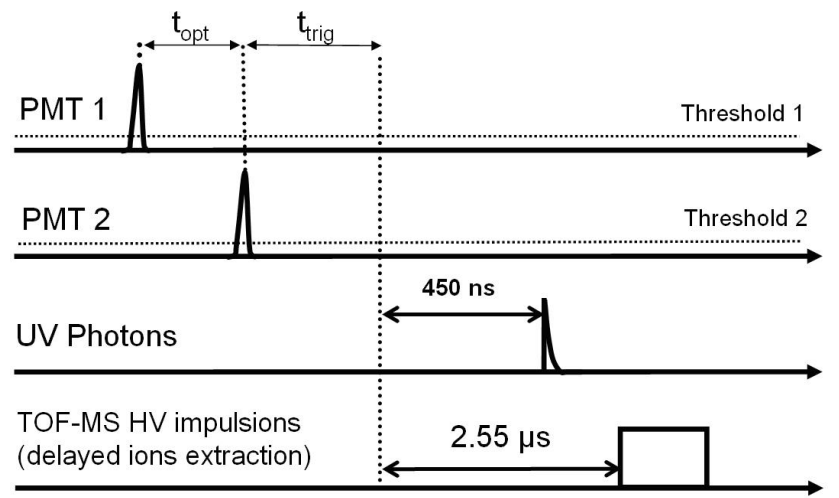

Fig. 6. Chronogram of the synchronization between optical detection and laser triggering.

will be emphasized in Sect. 3.2 by the study of the chemical composition of SOA formed by the ozonolysis of indene as first scientific application of SPLAM.

\subsection{Synchronization of optical detection and LDI mass spectrometry}

The synchronization between the optical detection and the desorption/ionization laser is achieved using a Field Programmable Gate Array card (FPGA, Avnet, ADS-XLXV4FX-EVL12-G). Figure 6 shows the chronogram of this process. The trigger time $t_{\text {trig }}$ is calculated in real time from the transit time $t_{\mathrm{opt}}$ of the particles between both continuous lasers. Since the trigger delay (i.e. the temporal separation between an external pulse and emission of photons) of the excimer laser is $450 \pm 5 \mathrm{~ns}$, this additional time delay has to be taken into account to exactly synchronize the impact of the UV photons to an arriving particle. Considering their measured particle velocities and the associate uncertainties, particles are expected to arrive in a $1.86 \times 1 \mathrm{~mm}$ area, homogeneous in energy, in the middle of the $7.5 \times 1 \mathrm{~mm}$ laser spot (see Sect. 2.3). Moreover, as already mentioned in the Sect. 2.3, a delay time of $2.55 \mu$ s is applied before extracting the produced ions in order to enhance mass resolution.

In the single particle mode of operation, the maximum analysis rate is 10 particles per second since at a higher repetition rate, the decrease of the excimer laser pulse energy is too important. Therefore, an upper limit of $10 \mathrm{~Hz}$ was programmed for the laser pulse repetition rate. In the current state of SPLAM, $t_{\mathrm{opt}}$, associated with the single particle mass spectrum, is not recorded yet. This has to be programmed in the future on the FPGA card, in order to investigate the particle composition size dependency and fully exploit the scientific potential of the SPLAM single particle measurement capacity.

\section{First results}

As explained before, the SPLAM instrument was designed to study the organic fraction of atmospheric aerosol particles. The study of SOA produced in the CESAM chamber, one of the LISA simulation chambers, was performed as the first application of SPLAM. Prior to this study, preliminary test experiments were performed using DOP particles in order to test the overall functioning and the feasibility of the synchronization procedure between the optical detection and the vaporization/ionization region of the instrument. These important tests are described first.

\subsection{Preliminary tests using DOP}

\subsubsection{Single particle mass spectra of DOP particles and their variability}

DOP (Sigma Aldrich, $>99 \%$ purity) particles were generated by nebulization of the pure viscous oil using a constant output atomizer (TSI, model 3076). Figure 7a shows a typical noise level on the mass spectra obtained for a single laser pulse when filtered $\mathrm{N}_{2}$ (Air Liquide) is introduced through the ALS inlet. The maximum and minimum thresholds of an ion signal to be considered as significant were calculated as three times the standard deviation obtained at each mass. These levels are presented as red shaded area on the panel a and a $4 \mathrm{mV}$ threshold was then determined for the whole spectra by excluding the higher noise located around $m / z 25$.

Figure $7 \mathrm{~b}$ shows a typical mass spectrum of an individual DOP particle. For this experiment, the produced particle concentration was diluted by a factor of 1000 . The laser power density was $1 \times 10^{8} \mathrm{~W} \mathrm{~cm}^{-2}$ with a $1 \mathrm{~mm}^{3}$ ionization volume.

Every single particle mass spectrum was repeatable in terms of peak position indicating that the TOF time scale is constant. As mentioned before, in its current state, the acquisition system does not allow to record the PMT signals and therefore, no link can be made between the particle diameter and the mass spectrum. However, from experimental observation of the variation of particles transit times $t_{\mathrm{opt}}$, the range of aerodynamic diameters of the sampled particles was determined independently to be comprised between $d_{\mathrm{aev}}=200$ and $900 \mathrm{~nm}$. The range of this sampling is consistent with the DOP size distribution measured by SMPS knowing that SPLAM optical DE is weak below $d_{\mathrm{aev}}=200 \mathrm{~nm}$.

Concerning the signal intensity repeatability, the mean intensity normalized to $\mathrm{m} / \mathrm{z} 57$ and associated standard deviation calculated from 50 single particle DOP mass spectra are indicated in red in Fig. 7b. As can be seen from these statistics, the fragment intensities of $\mathrm{m} / \mathrm{z} 261\left(\mathrm{C}_{16} \mathrm{H}_{21} \mathrm{O}_{3}^{+}\right), 167\left(\mathrm{C}_{8} \mathrm{H}_{7} \mathrm{O}_{4}^{+}\right), 149\left(\mathrm{C}_{8} \mathrm{H}_{5} \mathrm{O}_{3}^{+}\right), 113$ $\left(\mathrm{C}_{8} \mathrm{H}_{17}^{+}\right), 112\left(\mathrm{C}_{8} \mathrm{H}_{16}^{+}\right), 105\left(\mathrm{C}_{7} \mathrm{H}_{5} \mathrm{O}^{+}\right), 104\left(\mathrm{C}_{7} \mathrm{H}_{4} \mathrm{O}^{+}\right)$, 


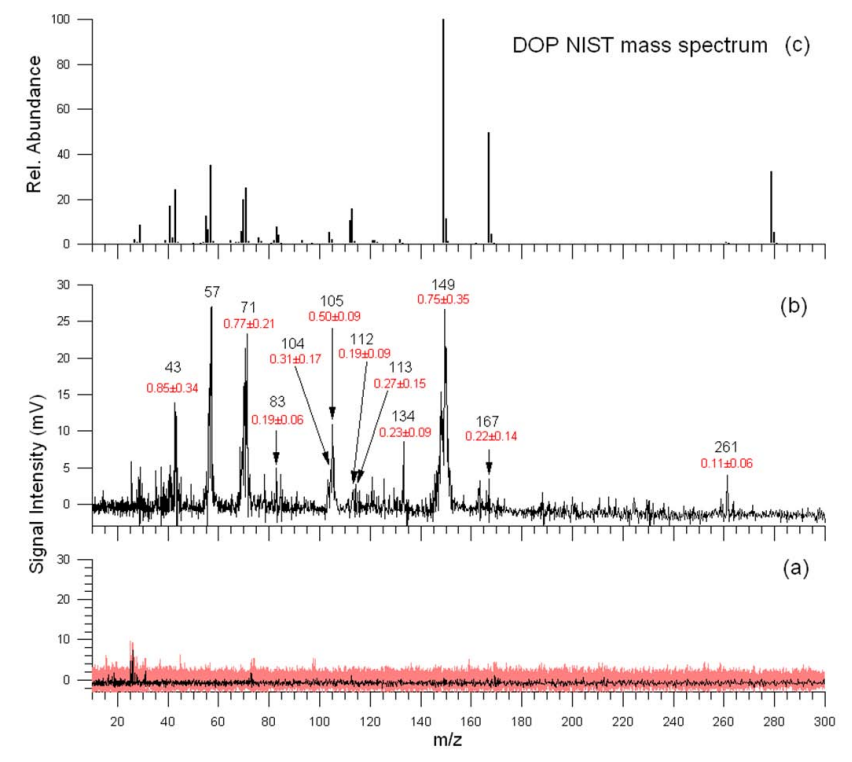

Fig. 7. (a) Typical noise level on the mass spectra obtained for a single laser pulse when aerodynamic lens system has sampled a filtered $\mathrm{N}_{2}$ flux. The red shaded area, calculated as three times the standard deviation obtained at each mass, corresponds to the maximum and minimum thresholds of an ion signal to be considered as significant, (b) typical mass spectrum of an individual DOP particle $\left(170<d_{\mathrm{aev}}<900 \mathrm{~nm}\right)$. The mean intensity ratios of each detected mass peak normalized to $m / z 57$ and their associated standard deviation (calculated from 50 single particle DOP mass spectra) are indicated in red below the mass peak identifications, (c) DOP NIST mass spectrum (electron ionization) (NIST, 2010).

$83\left(\mathrm{C}_{6} \mathrm{H}_{11}^{+}\right), 71\left(\mathrm{C}_{5} \mathrm{H}_{11}^{+}\right), 57\left(\mathrm{C}_{4} \mathrm{H}_{9}^{+}\right), 43\left(\mathrm{C}_{3} \mathrm{H}_{7}^{+}\right)$, which are typical cationic fragments of DOP (NIST, 2008), vary a lot. Nevertheless, the mass spectra resemble grossly the EI ionization mass spectrum of DOP found in the NIST data base (taken at $70 \mathrm{eV}$ electron energy) which is plotted for comparison in Fig. 7c. This means that dissociative ionization of DOP molecules is predominant with both ionization methods, EI ionization and LDI, since the DOP parent cation $(\mathrm{m} / \mathrm{z} 390)$ is not observed for example. The similarity of our DOP mass spectra with the EI-MS demonstrates that under LDI conditions, the amount of internal energy released to the parent cation is not far from to the one transferred during the EI process. However, there is one striking difference: in the EI-MS of DOP, $m / z 279$ is a strong ion $(25 \%$ relative to the base peak $\mathrm{m} / \mathrm{z}, 149)$ whereas this peak is absent in the single particle LDI mass spectra (taken at about $\sim 1.4 \times 10^{7} \mathrm{~W} \mathrm{~cm}^{-2}$ laser power irradiating the sample). This suggests that internal energy released to the parent cation might be slightly higher in our specific LDI conditions as compared to the $70 \mathrm{eV} \mathrm{EI}$ ionization process

The observed variability of our mass spectra, i.e. the variation of fragment ion intensity ratios, is a critical point that will be addressed in the following. It is inherent to the used desorption/ionization methodology and mainly attributed to two effects: (1) the variation of the pulse energy of the LDI laser and (2) the variation of the energy deposition inside the particle which can depend on the particle size and on its chemical nature.

Ad (1) The variation of the pulse energy of the LDI laser over time is typically $\pm 10 \%$ from pulse to pulse. This means that each particle does not receive exactly the same power density when being illuminated by the UV laser pulse. This fundamental problem is inherent to excimer lasers and cannot be solved easily, unless by using other type of lasers as for example the 4th harmonic of a Nd:Yag laser which can be more stable in pulse to pulse energy, but who has larger trigger delays $\left(t_{\text {trig }}\right)$ making it more difficult to use for single particle mass spectrometry. The only way to overcome this excimer laser shortcoming is to analyze large numbers of particles and to try to sort out the variability by statistics.

Ad (2) The variability of the DOP particle sizes could also explain peak intensity variations: even if the power deposited per unit of particle surface is the same for small and large particles (at constant pulse energy), the power received per unit of particle volume might be different for particles of different size. We also note that charge transfer processes occurring in the ablation plume depend on the aerosol matrix, and therefore on the chemical nature of the particles which thus is expected to influence the fragment ion intensity ratios observed in the LDI mass spectra. These effects can be minimized using L2DI where desorption and ionization are separated. They have been discussed, for example, by Lazar et al. (1999) and work cited there.

The main conclusion from analysis of our DOP preliminary study is that under LDI conditions, analysis of the single particle mass spectra of real world aerosols should be extremely careful and take into account the above cited effects, if possible. Nevertheless, typical ions of chemical substances in more or less significant intensity ratios are observed as can be seen in Fig. 7 and thus qualitative analysis of the aerosols is possible with LDI.

\subsubsection{Particle hit rate determination of SPLAM}

The global hit rate, which is defined as the ratio between the number of particles hit by the vaporization/ionization laser that generate ions detectable by the mass spectrometer, and the number of particles sized by the optical detection during the same time period, was determined to be $15 \%$ in these preliminary experiments. This corresponds to a typical hit rate obtained by other single particle aerosol mass spectrometers (Su et al., 2004; Zelenyuk et al., 2005). Unfortunately, approximately half of the single particle mass spectra exhibit very intense and unidentifiable broad mass peaks, appearing between $m / z 40$ and $m / z 65$ (not shown). This is explained as an ion extraction artifact inside the ion source of the TOF-MS. For these cases, the LDI ion plume is probably formed at the edge of the extraction region which 
does not allow proper extraction and space focalization of the ions. Therefore, these spectra have to be discarded and the effective hit rate, corresponding to the fraction of analyzable mass spectra, is thus estimated to be about $8 \%$.

We can conclude from these preliminary experiments using DOP particles that all three parts of our instrument (1) sampling a polydisperse aerosol using the aerodynamic lens system, (2) particles sizing by a two-fold optical detection, and (3) synchronization with LDI and measurement of single particle mass spectra by TOF-MS - work properly. The instrument is thus adapted for single particle analysis of organic aerosols. In order to scientifically validate the SPLAM instrument, we have analyzed a SOA formed in smog chamber experiment and main results are described in the following section.

\subsection{Study of aromatic SOA produced from indene ozonolysis}

\subsubsection{SOA production and sampling in the CESAM chamber}

Aromatic SOA were produced in the CESAM simulation chamber described elsewhere (Wang et al., 2011). A brief description is given here: the $4.2 \mathrm{~m}^{3}$ stainless steel chamber is equipped by a pumping system to deeply clean the chamber between experiments and to limit wall memory effects. An internal fan allows for homogeneous mixing of gaseous species and aerosols. In the case of the present indene ozonolysis study, the chamber was filled with $80 \% \mathrm{~N}_{2}$ (Air Liquide) and $20 \% \mathrm{O}_{2}$ (Alphagaz 1, Air Liquide) after several pumping cycles. A $1 \mathrm{ppm}$ concentration of ozone, produced by a UV lamp, was injected and controlled using an ozone analyzer (Horiba model APOA-370). The volatile precursor, indene (Sigma Aldrich, 99\% purity), was then injected to yield a $1 \mathrm{ppm}$ concentration. This aromatic precursor was chosen for its known high potential to form secondary organic aerosols (Chiappini, 2006). The temporal evolution of the size distribution of produced particles during this experiment was monitored using a Scanning Mobility Particle Sizer (TSI, DMA model $3080+$ CPC model 3010) and is presented in Fig. 8. Between the beginning and the end of this experiment, the mean diameter of the measured size distribution shifted from 80 to $100 \mathrm{~nm}$ with maximum number concentrations of $4 \times 10^{3}$ to $1 \times 10^{3}$ particles $\mathrm{cm}^{-3}$ respectively. As for DOP experiment, a separated aerodynamic sizing of the detected SOA particles was performed during this experiment, using the optical detection of the SPLAM instrument. This allowed to determine that the sampled $d_{\text {aev }}$ range was comprised between 170 and $900 \mathrm{~nm}$. This range was again consistent with the optical SPLAM DL and corresponds to the bigger particles formed inside the chamber, i.e. the upper part of the size distribution (see Fig. 8).

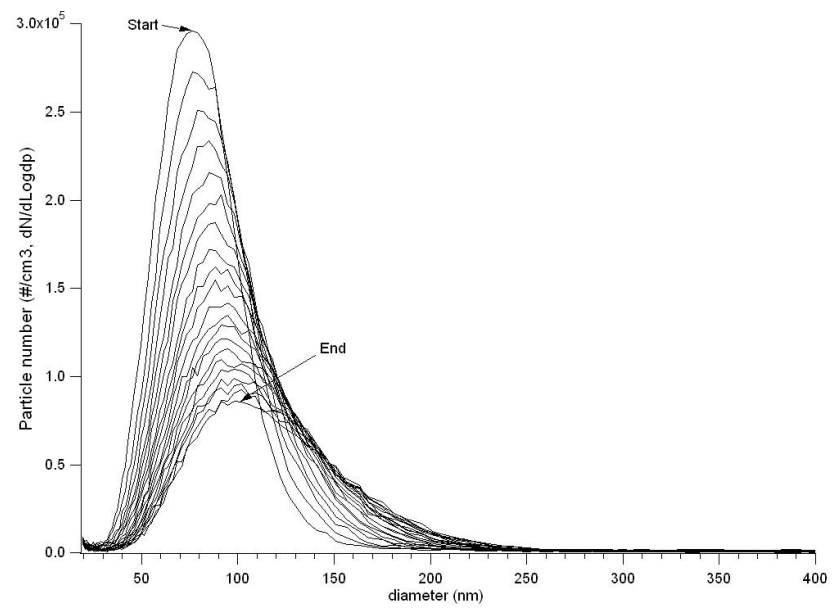

Fig. 8. Temporal evolution of the size distribution of produced SOA. Between the beginning and the end of this experiment, the mean diameter of the measured size distribution was shifted from 80 to $100 \mathrm{~nm}$ with maximum number concentrations of $4 \times 10^{3}$ to $1 \times 10^{3}$ particles $\mathrm{cm}^{-3}$ respectively.

\subsubsection{Characterization of the blank level}

The CESAM chamber was connected to SPLAM via a $4 \mathrm{~mm}$ inner diameter copper tube. The length of this tube was kept as short as possible (about $1.5 \mathrm{~m}$ ). Figure 9, lowest panel, shows the typical noise level of the SPLAM mass spectrum obtained for a single laser pulse when gas was sampled (SPLAM aerosol inlet open, CESAM chamber filled with synthetic air and ozone, but without indene). The red shaded area, presented on this panel, was calculated as three times the standard deviation obtained at each mass and corresponds to the maximum and minimum thresholds of an ion signal to be considered as significant. From this calculation, the maximum level was determined to be $4 \mathrm{mV}$. This level is also indicated as red shaded area in Fig. 10a and b.

\subsubsection{Single particle mass spectra and SOA chemical composition analysis}

During this five hours aerosol formation experiment, single particle mass spectra were obtained about two hours after ozone injection, with an effective hit rate of about $8 \%$ (cf. also Sect. 3.1.2). The analyzable mass spectra were subdivided in two groups taking into account the type of observed ions and their signal intensity. Figure 9a, $\mathrm{b}$ and $\mathrm{c}$ shows representative single particle mass spectra corresponding to a first group. About $80 \%$ of the analyzable mass spectra belong to this group which is characterized by three relatively intense signals for ions of $\mathrm{m} / z 39,57$ and 63. These fragments are assigned to organic cations formed by dissociative ionization of larger hydrocarbons (HC). For example, $m / z 63\left(\mathrm{C}_{5} \mathrm{H}_{3}^{+}\right)$is a typical fragment observed in the ionic fragmentation of aromatic $\mathrm{HC}$ which in turn makes 


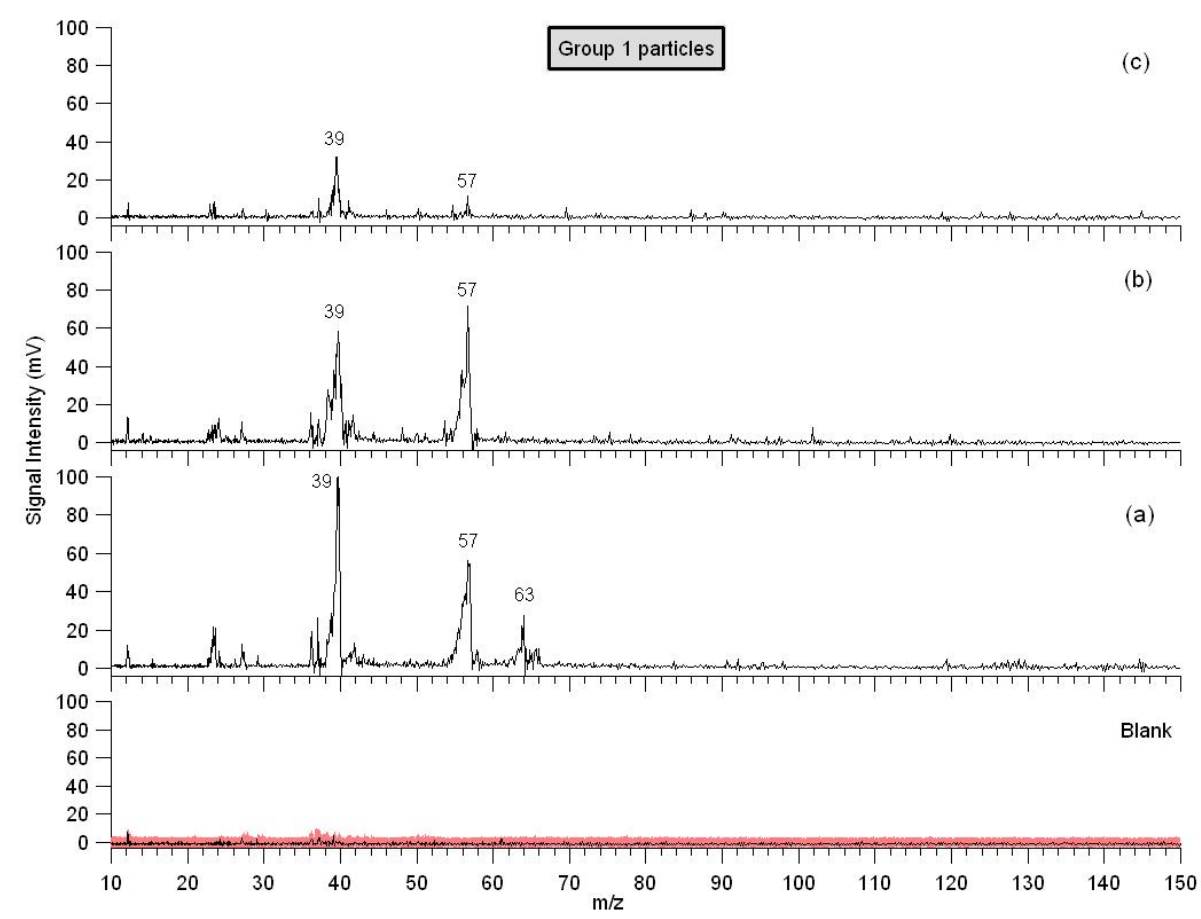

Fig. 9. Blank: typical noise level on the mass spectra obtained for a single laser pulse (SPLAM inlet open, CESAM chamber filled with synthetic air and ozone but without indene). The blank level is determined to be at $4 \mathrm{mV}$ (indicated as red shaded zone). See text for further explanations; (a), (b), (c): examples of three single particle mass spectra of SOA produced by ozonolysis of indene in the smog chamber CESAM (group 1 particles).

sense considering the chemical system under study. On the contrary, $m / z 39\left(\mathrm{C}_{3} \mathrm{H}_{3}^{+}\right)$and $m / z 57\left(\mathrm{C}_{4} \mathrm{H}_{9}^{+}\right)$are generally weak in the EI-MS fragmentation of aromatic HC. Theses two fragments are considered to be typical in the MS of aliphatic $\mathrm{HC}$ or molecules with aliphatic side chains.

Figure 10a and $\mathrm{b}$ correspond to representative mass spectra classified in a second group which contributes to about $20 \%$ of the analyzable mass spectra. The intensity scale of the spectra shown in Fig. 10a is different with respect to those shown in Fig. 10b, in order to better distinguish weak fragments. The peculiarity of the second group is that, in addition to $m / z 39,57$ and 63 , it presents fragments with higher $\mathrm{m} / z$ ratios, up to 280 . The $m / z 280$ ion (Fig. 10b-3) is the highest mass actually observed in our measurements.

From Fig. 10, one can easily notice that the obtained mass spectra of the second group do not resemble to each other. In principle, these differences could originate from real chemical difference of the particles. Since current understanding of SOA formation implies dynamic mechanisms of enrichment/depletion processes due to evaporation and condensation of compounds of different saturation vapor pressure (see for example Kroll and Seinfeld, 2008), chemical composition differences are expected to depend mostly on size. As discussed above, the LDI process itself yields a certain variability of mass spectra. The dependence of LDI fragmentation patterns on particle size could in principle be wiped out by classifying the observed mass spectra additionally by particle size (which is not possible yet with the present experimental setup). The dependence of LDI fragmentation patterns on the chemical nature of SOA condensed phase matrix is, as discussed above, uncertain. Therefore, in the absence of size-resolved MS measurements and more statistics, we cannot conclude on the detection of further chemical sub-groups among group 2 particles.

The $\mathrm{m} / \mathrm{z}$ ratios of the observed ions are indicated in Fig. 10 for each analyzed particle characterized by a different mass spectrum. The only common ions to all particles are $m / z 12\left(\mathrm{C}^{+}\right), 24\left(\mathrm{C}_{2}^{+}\right), 27\left(\mathrm{C}_{2} \mathrm{H}_{3}^{+}\right)$, and $39\left(\mathrm{C}_{3} \mathrm{H}_{3}^{+}\right)$. At this point we have to consider what type of semi-volatile and non-volatile degradation products can be expected to be formed during the ozonolysis of indene and which kind of fragments they can produce during dissociative ionization. The $\mathrm{O}_{3}$ /indene chemical system has been studied earlier by Chiappini et al. (2006). In this study, the SOA particles were sampled on glass fiber filters and subsequently analyzed by supercritical fluid extraction coupled to GC-MS analysis of BSTFA derivatized compounds (Chiappini et al., 2006). Ten different degradation products have been identified using this technique.

In the literature, $\mathrm{EI}(70 \mathrm{eV})$ and $\mathrm{PI}(15 \mathrm{eV})$ reference mass spectra can be found only for benzoic acid, phthaldialdehyde 

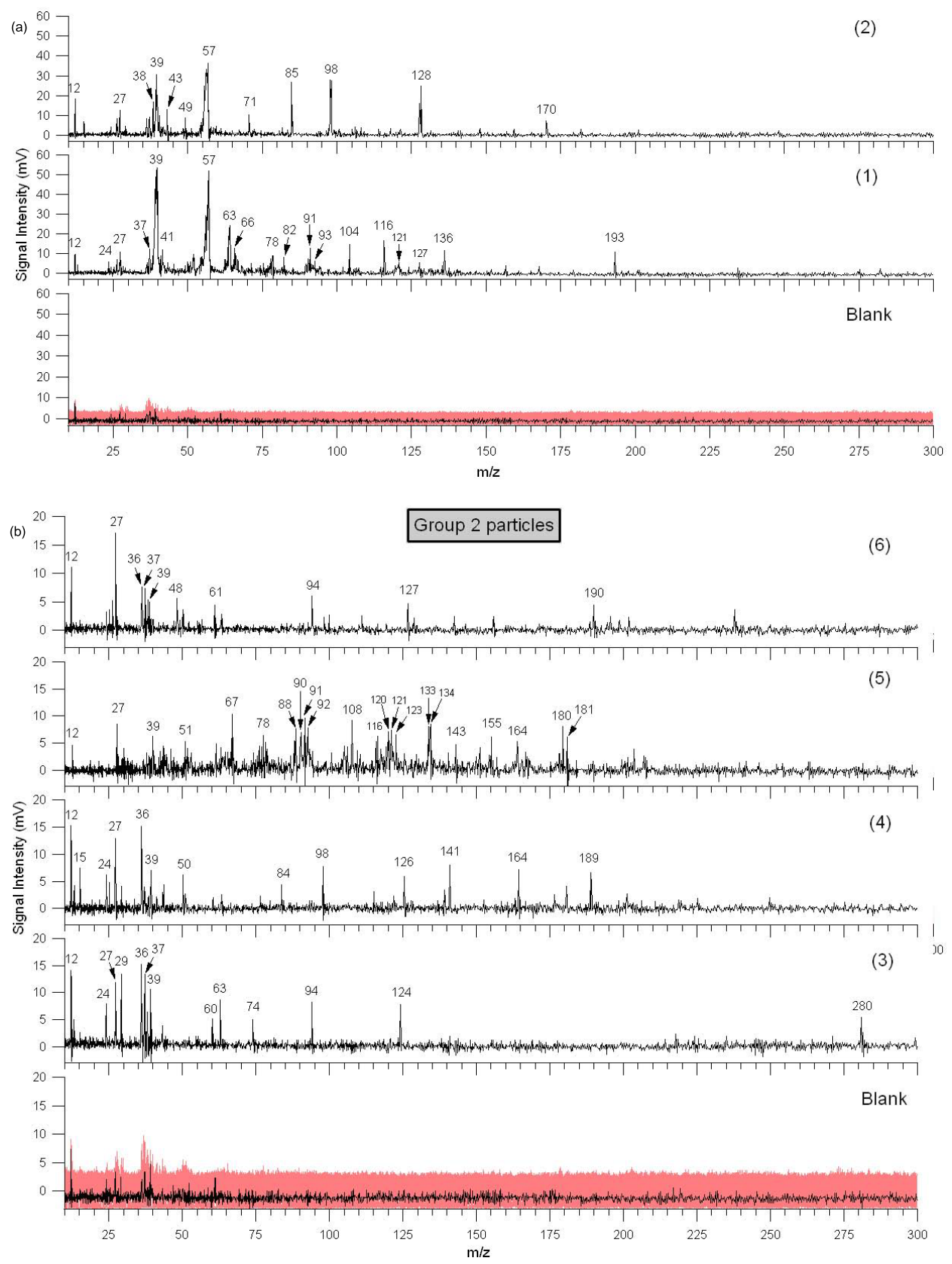

Fig. 10. Six single particle mass spectra of SOA produced by ozonolysis of indene in the smog chamber CESAM (group 2 particles). (a) and (b) have different ordinate scaling. The blank level is determined to be at $4 \mathrm{mV}$ (indicated as red shaded zone in the lowest panels). See text for further explanations.

and phthalic acid (NIST, 2008; Gaie-Levrel et al., 2008). Under these conditions, it is very difficult to proceed to molecular speciation from our single particle mass spectra. Also, more statistics are needed in order to measure the frequency of occurrence of certain type of single particle mass spectra.

The expected ions for benzoic acid are $m / z 122,105$, 77, 51 (NIST, 2008). Only ion of $m / z 51$ is found in the MS no. 5 (Fig. 10b). Photoionization at $15 \mathrm{eV}$ of phthaldialdeyde gives rise to principal ions $m / z 134\left(\mathrm{M}^{+}\right)$, $106\left(\mathrm{C}_{7} \mathrm{H}_{6} \mathrm{O}^{+}\right), 105\left(\mathrm{C}_{7} \mathrm{H}_{5} \mathrm{O}^{+}\right), 78\left(\mathrm{C}_{6} \mathrm{H}_{6}^{+}\right), 77\left(\mathrm{C}_{6} \mathrm{H}_{5}^{+}\right)$, and $51\left(\mathrm{C}_{4} \mathrm{H}_{3}^{+}\right)$(Gaie-Levrel et al., 2008). The mass spectrum no. 5 (Fig. 10b) shows three of these ions $(\mathrm{m} / \mathrm{z} 134,78,51)$. Phthalic acid gives rise to principal ions $m / z 166\left(\mathrm{M}^{+}\right), 148$ $\left(\mathrm{C}_{8} \mathrm{H}_{4} \mathrm{O}_{3}^{+}\right), 104\left(\mathrm{C}_{7} \mathrm{H}_{4} \mathrm{O}^{+}\right)$, and $76\left(\mathrm{C}_{6} \mathrm{H}_{4}^{+}\right)$at $15 \mathrm{eV}$ PI. Only ion of $m / z 104$ is observed in the single particle MS no. 1 in Fig. 10a. 
In the work of Gaie-Levrel et al. (2008), the dissociative photoionization of o-tolualdehyde, 2-methylphenol and o-toluic acid has also been studied. These three compounds were observed as constituents of SOA formed by 2-methylstyrene oxidation with ozone but not by indene as aerosol precursor (Chiappini, 2006). We note, however, that most of the expected principal ions from o-tolualdehyde $(\mathrm{m} / \mathrm{z}, 120,119,92), 2$-methylphenol $(\mathrm{m} / \mathrm{z} 108,107,91,90,89$, $80,79)$ and o-toluic acid $(\mathrm{m} / \mathrm{z}=136,119,118,91,90,89)$ are observed in our single particle group 2 mass spectra. Yet, we cannot claim that these three compounds were positively identified here in the absence of reference mass spectra in the same LDI conditions (in terms of power density) and size resolved measurements.

At this stage we cannot explain all the ions observed in group 2 mass spectra and a complete molecular speciation is apparently not possible. However, typical ions for expected indene degradation products were observed. Furthermore, high molecular weight ions $m / z 280$ (MS no. 3), 193 (MS no. 1), 190 (MS no. 6), 189 (MS no. 4), 181, 180 (MS no. 5) and 170 (MS no. 2) observed for each particle of the second group cannot be attributed for the moment. They might belong to cations formed by ionization of other non-identified products or even of organic oligomers which could be present in the indene SOA.

\subsubsection{Discussion of the first results of SPLAM and comparison to current literature}

Even though dissociative ionization of the molecules present in the aerosol phase is predominant during the LDI process, the SPLAM instrument has detected high molecular weight ions originating from indene degradation products in the particulate phase.

There are very few studies in the literature where lab-produced SOA from organic precursors have been analyzed by single particle LDI mass spectrometry. To our best knowledge, Narukawa et al. (2007) and Huang et al. (2007) are the only ones.

Huang et al. (2007) investigated SOA formation initiated by $\mathrm{OH}$ photooxidation of five monocyclic aromatic hydrocarbons: benzene, toluene, ethylbenzene, p-xylene, and 1,2,4-trimethylbenzene using single particle LDI mass spectrometry. These authors analyzed a few hundreds of mass spectra for each of the five types of SOA and determined an appearance frequency distribution for the eight main mass peaks $(\mathrm{m} / \mathrm{z}, 18,29,43,44,46,57,67$, 77). For all five types of SOA, $m / z 57$ is by far the most abundant mass peak. On the contrary, $m / z 39$ and 63 which are observed in our group 1 mass spectra $(80 \%$ of all analyzable MS in our study) are much less frequent in the experiments of Huang et al. (2007). This could be due to the different precursor in our study. It is interesting to note that these authors also observe many high molecular weight ions (up to $m / z$ 186) despite the fragmentation induced by
LDI. However, these ions seem to be less abundant since they do unfortunately not appear in their appearance frequency analysis. Their measurements are qualitatively in accordance with our results since in our study only $20 \%$ of the single particle MS show ions with higher $m / z$ ratios.

Narukawa et al. (2007) investigated the ozonolysis of cyclohexene using single particle LDI mass spectrometry. These authors focus on the negative ion mass spectra and reveal formation of dicaboxylic acid $[\mathrm{M}-\mathrm{H}]^{-}$molecular related ions using their own reference spectra. The latter are produced by nebulizing aqueous solutions of pure dicarboxylic acid solutions. Their work shows nicely that negative ion LDI mass spectra can yield molecular speciation. However, Narukawa et al. (2007) do not make an ion frequency of occurrence analysis and intense signals for negative ions from their "representative" mass spectra remain unexplained. Furthermore, their one-laser optical detection is not able to deliver size-resolved mass spectrometric measurements. Surprisingly, the positive ion mass spectra of Narukawa et al. (2007) only reveal $\mathrm{m} / \mathrm{z}, 12,27,39$ and 57 but not higher $\mathrm{m} / \mathrm{z}$ ions. This might be due to a slightly higher power density used in their study as compared to ours, or lower sensitivity of the mass analyzer.

There are quite a few single particle studies in the literature analyzing particles containing polycyclic aromatic hydrocarbons (PAH) and combustion type aerosols (Lazar et al., 1999; Rodgers et al., 2000; Bente et al., 2008, 2009). It is not very useful to compare our results to these studies since the condensed phase matrix, influencing the LDI-MS, is supposed to be very different in this type of aerosols. Furthermore, PAHs form very stable molecular cations, relatively easy to analyze.

Finally, we can compare single particle results to SOA studies using the Aerodyne aerosol mass spectrometer (AMS) which uses EI ionization and thermal desorption (TD) of aerosols (Bahreini et al., 2005; Alfarra et al., 2006). Indeed, the studies investigating lab-produced SOA involving this instrument give rise to a very high fragmentation level and common dominant fragments at $\mathrm{m} / \mathrm{z} 41,43,44$ and 55 are observed in all mass spectra. Our study and the one of Huang et al. (2007) thus suggests that molecular fragmentation induced by LDI is less important than in the TD-EI-MS methodology, since higher $\mathrm{m} / \mathrm{z}$ ions are observed.

\section{Conclusions}

A single particle aerosol mass spectrometer, called SPLAM (Single Particle Laser Ablation Mass Spectrometry), equipped with an aerodynamic lens system, a two-laser optical detection and a $1 \mathrm{~m}$ linear TOF-MS, has been developed, calibrated and characterized. The instrument was designed to detect and analyze sub-micrometer sized organic aerosol particles. The transmission of the aerodynamic lens 
system has been modeled and designed using the program developed by Wang et al. (2006). The lens transmits particles with diameters comprised between $200 \mathrm{~nm}$ and $4 \mu \mathrm{m}$ with a theoretical efficiency of $100 \%$ in a beam of very low divergence (diameter $<1 \mathrm{~mm}$ at the ion source). The optical detection limit in terms of particle size was determined to be at $100 \mathrm{~nm}$ approximately. The two-laser optical detection efficiency $\mathrm{DE}$ is measured to be $0.4 \%$ at $d_{\mathrm{aev}}=100 \mathrm{~nm}$ and $74 \%$ at $d_{\mathrm{aev}}=350 \mathrm{~nm}$. After aerodynamic sizing, the particles enter the TOF-MS which is equipped with an excimer laser emitting at $\lambda=248 \mathrm{~nm}$ used for one step laser desorption/ionization (LDI). The mass resolution is $m / \Delta m=500$. The laser is triggered by the optical particle detection upstream. The three stage differential pumping of SPLAM excludes any detection of gas phase compounds.

The instrument has been fully characterized and scientifically validated by a study of SOA produced in a smog chamber from ozonolysis of indene. The global hit rate is $15 \%$ and the fraction of analyzable mass spectra is $8 \%$. The latter were classified in two groups. The first group, which represents $80 \%$ of the analyzable mass spectra, is characterized by three relatively intense signals for ions of $\mathrm{m} / z 39,57$ and 63 while a second group additionally presents fragments with higher $\mathrm{m} / \mathrm{z}$ ratios, up to 280 and represents $20 \%$ of the total mass spectra. Group 2 mass spectra are very different from one to another. This could reflect different chemical types of particles to be present in the indene SOA. However, as we can conclude from our study, under LDI conditions $\left(1.4 \mathrm{~W} \mathrm{~cm}^{-2}\right.$ irradiation power density at $\lambda=248 \mathrm{~nm}$ ) size-resolved mass spectra are needed in the future in order (a) to clarify (and eliminate) the influence of the particle size on molecular fragmentation patterns and (b) relate possible chemical difference to enrichment/depletion processes in the SOA formation process.

Furthermore, LDI studies of SOA need adapted reference spectra in order to proceed to molecular speciation. It is probably best to produce them by forming aerosols by nebulization of the pure substances to be expected in the formed SOA, as has been done by Narukawa et al. (2007), but we note that reference compounds are not always easily available.

Our results have been compared to those of Huang et al. (2007) who recently studied SOA formed from photooxidation of aromatic monocycles using LDI single particle TOF-MS. These authors analyze hundreds of single particle MS by calculating the frequency of occurrence of ions. Similar to our results, small ions, with $m / z, 29,43,44$, 57 and 77 dominate the mass spectra of Huang et al. (2007). Interestingly, in both studies, theirs and ours, high molecular weight ions, many with the same $\mathrm{m} / \mathrm{z}$ ratios, are also observed but with lower frequency of occurrence.

More generally, it has to be noted also that signal to noise ratios in single particle mass spectrometry of sub-micrometer sized and chemically complex particles are very low, even when very sensitive detection techniques are used. A statistic evaluation, over at least a few hundreds of particles, is necessary to understand the real chemical meaning of the mass spectra. The real-time character of this type of measurements is then somewhat reduced. For example, if a few hundred particles are needed for chemical analysis, the maximum time resolution would be a few minutes with the current particle analysis rate.

Different experimental approaches are also possible to proceed towards molecular speciation with SPLAM, for example the use of L2DI or SPI. Both techniques permit ionization of molecules close to their ionization threshold and therefore reduce the number of dissociative ionization reactions. Molecular speciation is probably more straightforward in these conditions since fewer fragments will appear per molecule. As an example, SPI using synchrotron radiation, coupled to flash vaporization on a heated surface, has been used recently with success to chemically analyze ensemble of nanoparticles (Mysak et al., 2005; Wilson et al., 2006; Gloaguen et al., 2006; Gaie-Levrel et al., 2011).

Finally, we can conclude that SPLAM with one-step LDI using a $\lambda=248 \mathrm{~nm}$ excimer laser has to be further developed, especially the particle size measurement has to be implemented. In relation with much more statistics and adapted LDI reference spectra, the study of an aromatic SOA should then gain interesting insights into the related aerosol formation processes (formation of oligomers, dynamic processes). For other types of SOA, formed from non-aromatic precursors, other experimental approaches like L2DI or SPI are probably necessary to be implemented.

Acknowledgements. Financial support was provided by the French Ministry of Research (ACI Nouvelles Méthodologies et Capteurs), the Ministry of Environment (PRIMEQUAL program), the Ile-De-France Region (SESAME program) as well as the CNRS (INSU, PNCA). The authors want to thank CNRS-INSU for supporting CESAM as a National Instrument and Jean-François Doussin for fruitful collaboration and encouraging support. This work was also supported by the EC within the I3 projects "Integrating of European Simulation Chambers for Investigating Atmospheric Processes" (EUROCHAMP-1, contract no. 505968). Warm thanks go to Xiaoliang Wang (now at Desert Research Institute, Nevada) for very helpful discussions about his aerodynamic lens model as well as to Eric Villenave (University of Bordeaux) for accompanying the whole project with valuable advices.

Edited by: H. Herrmann

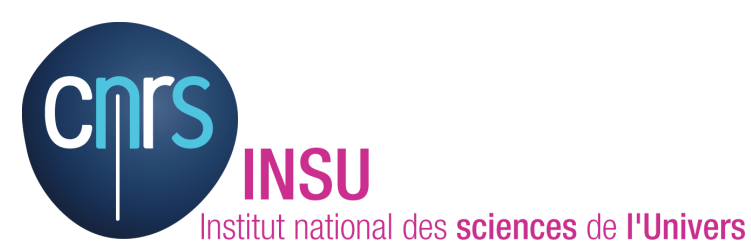

The publication of this article is financed by CNRS-INSU. 


\section{References}

Alfarra, M. R., Paulsen, D., Gysel, M., Garforth, A. A., Dommen, J., Prévôt, A. S. H., Worsnop, D. R., Baltensperger, U., and Coe, H.: A mass spectrometric study of secondary organic aerosols formed from the photooxidation of anthropogenic and biogenic precursors in a reaction chamber, Atmos. Chem. Phys., 6, 52795293, doi:10.5194/acp-6-5279-2006, 2006.

Allen, J. and Gould, R. K.: Mass spectrometric analyzer for individual aerosol particles, Rev. Sci. Instrum., 52, 804-809, 1981.

Bahreini, R., Keywood, M. D., Ng, N. L., Varutbangkul, V., Gao, S., Flagan, R. C., Seinfeld, J. H., Worsnop, D. R., and Jimenez, J. L.: Measurements of Secondary Organic Aerosol from Oxidation of Cycloalkenes, Terpenes, and m-Xylene Using an Aerodyne Aerosol Mass Spectrometer, Environ. Sci. Technol., 39, 56745688, 2005.

Bente, M., Sklorz, M., Streibel, T., and Zimmermann, R.: Online Laser Desorption-Multiphoton Postionization Mass Spectrometry of Individual Aerosol Particles: Molecular Source Indicators for Particles Emitted from Different Traffic-Related and Wood Combustion Sources, Anal. Chem., 80, 8991-9004, 2008.

Bente, M., Sklorz, M., Streibel, T., and Zimmermann, R.: Thermal Desorption-Multiphoton Ionization Time-of-Flight Mass Spectrometry of Individual Aerosol Particles: A Simplified Approach for Online Single-Particle Analysis of Polycyclic Aromatic Hydrocarbons and Their Derivatives, Anal. Chem., 81, 2525-2536, 2009.

Cabalo, J., Zelenyuk, A., Baer, T., and Miller, R. E.: Two-Color Laser InducedEvaporation Dynamics of Liquid Aerosols Probed by Time-of-Flight Mass Spectrometry, Aerosol Sci. Tech., 33, 3-19, 2000.

Canagaratna, M. R. Jayne, J. T., Jimenez, J. L., Allan, J. D., Alfarra, M. R., Zhang, Q., Onasch, T. B., Drewnick, F., Coe, H., Middlebrook, A., Delia, A., Williams, L. R., Trimborn, A. M., Northway, M. J., DeCarlo, P. F., Kolb, C. E., Davidovits, P., and Worsnop, D. R.: Chemical and microphysical characterization of ambient aerosols with the Aerodyne aerosol mass spectrometer, Mass Spectrom. Rev., 26, 185-222, 2007.

Carson, P. G., Neubauer, K. R., Johnston, M. V., and Wexler, A. S.: Online Chemical-Analysis of Aerosols by Rapid Single-Particle Mass-Spectrometry, J. Aerosol Sci., 26, 535-545, 1995.

Chiappini, L.: Développement d'une technique d'analyse pour l'étude de la composition chimique et des voies de formation de l'aérosol organique secondaire en atmosphère simulée, $\mathrm{PhD}$ Thesis, 2006 (in French).

Chiappini, L., Perraudin, E., Durand-Jolibois, R., and Doussin, J.-F.: Development of a supercritical fluid extraction-gas chromatography-mass spectrometry method for the identification of highly polar compounds in secondary organic aerosols formed from biogenic hydrocarbons in smog chamber experiments, Anal. Bioanal. Chem., 386, 1749-1759, 2006.

Chung, S. H. and Seinfeld, J. H.: Global distribution and climate forcing of carbonaceous aerosols, J. Geophys. Res., 107, 44074440, 2002.

Cocker III, D. R., Mader, B. T., Kalberer, M., Flagan, R. C., and Seinfeld, J. H.: The effect of water on gas-particle partitioning of secondary organic aerosol: II. m-xylene and 1,3,5-trimethylbenzene photooxidation systems, Atmos.
Environ., 35, 6073-6085, 2001.

Davis, W. D.: Surface ionization mass spectroscopy of airborn particulates, J. Vac. Sci. Technol., 10, 278-285, 1973.

DeCarlo, P. F., Slowik, J. G., Worsnop, D. R., Davidovits, P., and Jimenez, J. L.: Particle morphology and density characterization by combined mobility and aerodynamic diameter measurements, Part 1: Theory, Aerosol Sci. Tech., 38, 1185-1205, 2004.

Drewnick, F., Hings, S. S., DeCarlo, P., Jayne, J. T., Gonin, M., Fuhrer, K., Weimer, S., Jimenez, J. L., Demerjian, K. L., Borrmann, S., and Worsnop, D. R.: A New Time-of-Flight Aerosol Mass Spectrometer (TOF-AMS) Instrument Description and First Field Deployment, Aerosol Sci. Tech., 39, 637-658, 2005.

Gaie-Levrel, F.: Développement d'un instrument d'analyse physico-chimique en temps réel pour l'étude de la fraction organique de l'aérosol atmosphérique: SPLAM - Single Particle Laser Ablation Mass Spectrometry, PhD Thesis, 2009 (in French).

Gaie-Levrel, F., Gutlé, C., Jochims, H.-W., Rühl, E., and Schwell, M.: Photoionization of Atmospheric Aerosol Constituents and Precursors in the 7-15eV Energy Region: Experimental and Theoretical Study, J. Phys. Chem. A, 112, 5138-5151, 2008.

Gaie-Levrel, F., Schwell, M., Garcia, G., and Nahon, L.: VUV state-selected photoionization of thermally-desorbed biomolecules by coupling an aerosol source to an imaging photoelectron/photoion coincidence spectrometer: case of the amino-acids tryptophan and phenylalanine, Phys. Chem. Chem. Phys., 13, 7024-7036, 2011.

Gard, E., Mayer, J. E., Morrical, B. D., Dienes, T., Fergenson, D. P., and Prather, K.: Real-time analysis of individual atmospheric aerosol particles: Design and performance of a portable ATOFMS, Anal. Chem., 69, 4083-4091, 1997.

Gloaguen, E., Mysak, E., Leone, S. R., Ahmed, M., and Wilson, K. R.: Investigating the chemical composition of miexed organic-inorganic particles by "soft" vaccuum ultraviolet photoionization: the reaction of ozone with anthracene on sodium chloride particles, Int. J. Mass Spectrom., 258, 74-85, 2006.

Gómez-González, Y., Surratt, J. D., Cuyckens, F., Szmigielski, R., Vermeylen, R., Jaoui, M., Lewandowski, M., Offenberg, J. H., Kleindienst, T. E., Edney, E. O., Blockhuys, F., Van Alsenoy, C., Maenhaut, W., and Claeys, M.: Characterization of organosulfates from the photooxidation of isoprene and unsaturated fatty acids in ambient aerosol using liquid chromatography/(-) electrospray ionization mass spectrometry, J. Mass Spectrom., 43, 371-382, 2008.

Gross, D. S., Gälli, M. E., Kalberer, M., Prévôt, A. S. H., Dommen, J., Alfarra, M. R., Duplissy, J., Gaeggeler, K., Gascho, A., Metzger, A., and Baltensperger, U.: Real time measurement of oligomeric species in secondary organic aerosol with the aerosol time-of-flight mass spectrometer, Anal. Chem., 78, 2130-2137, 2006.

Hallquist, M., Wenger, J. C., Baltensperger, U., Rudich, Y., Simpson, D., Claeys, M., Dommen, J., Donahue, N. M., George, C., Goldstein, A. H., Hamilton, J. F., Herrmann, H., Hoffmann, T., Iinuma, Y., Jang, M., Jenkin, M. E., Jimenez, J. L., Kiendler-Scharr, A., Maenhaut, W., McFiggans, G., Mentel, Th. F., Monod, A., Prévôt, A. S. H., Seinfeld, J. H., Surratt, J. D., Szmigielski, R., and Wildt, J.: The formation, 
properties and impact of secondary organic aerosol: current and emerging issues, Atmos. Chem. Phys., 9, 5155-5236, doi:10.5194/acp-9-5155-2009, 2009.

Hamilton, J. F., Lewis, A. C., Carey, T. J., and Wenger, J. C.: Characterization of polar compounds and oligomers in secondary organic aerosol using liquid chromatography coupled to mass spectrometry, Anal. Chem., 80, 474-480, 2008.

Hinz, K. P., Kaufmann, R., and Spengler, B.: Laser-Induced Mass Analysis of Single Particles in the Airborne State, Anal. Chem., 66, 2071-2076, 1994.

Hoffmann, T., Bandur, R., Hoffmann, S., and Warscheid, B.: On-Line Characterization of Gaseous and Particulate Organic Analytes Using Atmospheric Pressure Chemical Ionization Mass Spectrometry, Spectrochim. Acta B, 57, 1635-1647, 2002.

Huang, M., Zhang, W., Hao, L., Wang, Z., Zhao, W., Gu, X., Guo, X., Liu, X., Long, B., and Fang, L.: Laser desorption/ionization mass spectrometric study of secondary organic aerosol formed from the photooxidation of aromatics, J. Atmos. Chem., 58, 237252, 2007.

Hunt, A. L. and Petrucci, G. A.: Analysis of ultrafine and organic particles by aerosol mass spectrometry, Trac-Trends in Anal. Chem., 21, 74-81, 2002.

IPCC (International Panel on Climate Change), Forster, P., Ramaswamy, V., Artaxo, P., Berntsen, T., Betts, R., Fahey, D. W., Haywood, J., Lean, J., Lowe, D. C., Myhre, G., Nganga, J., Prinn, R., Raga, G., Schulz, M., and Van Dorland, R.: Changes in Atmospheric constituents and in radiative forcing, in: Climate Change 2007: The Physical Science Basis, Contribution of Working Group I to the Fourth Assessment Report of the Intergouvernmental Panel on Climate Change); Cambridge University Press: Cambridge, 2007.

Jayne, J. T., Leard, D. C., Zhang, X. F., Davidovits, P., Smith, K. A., Kolb, C. E., and Worsnop, D. R.: Development of an Aerosol Mass Spectrometer for Size and Composition Analysis of Submicron Particles, Aerosol Sci. Tech., 33, 49-70, 2000.

Jimenez, J. L.: Aerosol Mass Spectrometry Part 2: Thermal desorption techniques, American association for aerosol research (AAAR), Annual Conference, Atlanta, GA, 2004.

Kanakidou, M., Seinfeld, J. H., Pandis, S. N., Barnes, I., Dentener, F. J., Facchini, M. C., Van Dingenen, R., Ervens, B., Nenes, A., Nielsen, C. J., Swietlicki, E., Putaud, J. P., Balkanski, Y., Fuzzi, S., Horth, J., Moortgat, G. K., Winterhalter, R., Myhre, C. E. L., Tsigaridis, K., Vignati, E., Stephanou, E. G., and Wilson, J.: Organic aerosol and global climate modelling: a review, Atmos. Chem. Phys., 5, 1053-1123, doi:10.5194/acp-5-1053-2005, 2005.

Kroll, J. H. and Seinfeld, J. H.: Chemistry of secondary organic aerosol: Formation and evolution of low-volatility organics in the atmosphere, Atmos. Environ., 42, 3593-3624, 2008.

Lassiter, W. S. and Moen, A. L.: In situ mass analysis of particles by surface-ionization mass spectrometry, NASA Technical Memorandum X-3112, 1-15, 1974.

Lazar, A. C., Reilly, P. T. A., Whitten, W. B., and Ramsey, J. M.: Real-time surface analysis of individual airborne environmental particles, Environ. Sci. Technol., 33, 3993-4001, 1999.

Liu, P., Ziemann, P. J., Kittelson, D. B., and McMurry, P. H.: Generating Particle Beams of Controlled Dimensions and Divergence: I. Theory of Particle Motion in Aerodynamic Lenses and Nozzle Expansions, Aerosol Sci. Tech., 22, 293-313, 1995a.
Liu, P., Ziemann, P. J., Kittelson, D. B., and McMurry, P. H.: Generating Particle Beams of Controlled Dimensions and Divergence: II. Experimental Evaluation of Particle Motion in Aerodynamic Lenses and Nozzle Expansions, Aerosol Sci. Tech., 22, 314-324, 1995b.

McKeown, P. J., Johnston, M. V., and Murphy, D. M.: Online Single-Particle Analysis by Laser Desorption MassSpectrometry, Anal. Chem., 63, 2069-2073, 1991.

Morrical, B. D., Fergenson, D. P., and Prather, K. A.: Coupling twoStep laser desorption/ionization with aerosol time-of-flight mass spectrometry for the analysis of individual organic particles, J. Am. Soc. Mass Spectr., 9, 1068-1073, 1998.

Mühlberger, F., Wieser, J., Ulrich, A., and Zimmermann, R.: Single photon ionization (SPI) via incoherent VUV-Excimer light: Robust and compact Time-of-flight mass spectrometer for on-line, real-time process gas analysis, Anal. Chem., 74, 3790-3801, 2002.

Mühlberger, F., Wieser, J., Ulrich, A., and Zimmermann, R.: Single photon ionization mass qpectrometry with a novel electron-pumped excimer lamp for detection of trac compounds from thermal processes, Organohalogen Compd., 66, 795-799, 2004.

Murphy, D. M. and Thomson, D. S.: Laser Ionization Mass-Spectroscopy of Single Aerosol-Particles, Aerosol Sci. Tech., 22, 237-249, 1995.

Murphy, D. M., Thomson, D. S., and Mahoney, M. J.: In Situ Measurements of Organics, Meteoritic Material, Mercury, and Other Elements in Aerosols at 5 to 19 Kilometers, Science, 282, 1664-1669, 1998.

Myers, R. L. and Fite, W. L.: Electrical detection of airborn particulates using surface ionization techniques, Environ. Sci. Technol., 9, 334-336, 1975.

Mysak, E., Wilson, K. R., Jimenez-Cruz, M., Ahmed, M., and Baer, T.: Synchrotron radiation based Aerosol Time-of-Flight Mass spectrometry for organic constituents, Anal. Chem., 77, 5953-5960, 2005

Narukawa, M., Matsumi, J., Matsumoto, J., Takahashi, K., Yabushita, A., Sato, K., Imamura, T.: Real-Time Analysis of Secondary Organic Aerosol Particles Formed from Cyclohexene Ozonolysis Using a Laser-Ionization Single-Particle Aerosol Mass Spectrometer, Anal. Sci., 23, 507-512, 2007.

NIST Mass Spec Data Center, Stein, S. E., director, "Mass Spectra" in NIST Chemical WebBook, Standard NIST reference database Number 69, National Institute of Standards and Technology, edited by: Linstrom, P. J. and Mallard, W. G., Gaithersburg MD, 20899, available at: http://webbook.nist.gov, 2008.

Noble, C. A. and Prather, K.: Real-time measurement of correlated size and composition profiles of individual atmospheric aerosol particles, Environ. Sci. Technol., 30, 2667-2680, 1996.

Noble, C. A., Nordmeyer, T., Salt, K., Morrical, B., and Prather, K. A.: Aerosol Characterization Using Mass Spectrometry, TrACTrend. Anal. Chem., 13, 218-222, 1994.

Nordmeyer, T. and Prather, K. A.: Real-Time Measurement Capabilities Using Aerosol Time-of-Flight Mass Spectrometry, Anal. Chem., 66, 3540-3542, 1994.

Prather, K. A., Nordmeyer, T., and Salt, K.: Real-time characterization of individual aerosol using time-of-flight mass spectrometry., Anal. Chem., 66, 1403-1407, 1994.

Reents, W. D., Downey, S. W., Emerson, A. B., Mujsce, A. M., 
Muller, A. J., Siconolfi, D. J., Sinclair, J. D., and Swanson, A. G.: Single-Particle Characterization by Time-of-Flight Mass-Spectrometry, Aerosol Sci. Tech., 23, 263-270, 1995.

Rodgers, R. P., Lazar, A. C., Reilly, P. T. A., Whitten, W. B., and Ramsey, J. M.: Direct Determination of Soil Surface-Bound Polycyclic Aromatic Hydrocarbons in Petroleum-Contaminated Soils by Real-Time Aerosol Mass Spectrometry, Anal. Chem., 72, 5040-5046, 2000.

Shu, J., Gao, S., and Li, Y.: A VUV Photoionization Aerosol Timeof-Flight Mass Spectrometer with a RF-Powered VUV Lamp for Laboratory-Based Organic Aerosol Measurements, Aerosol Sci. Tech., 42, 110-113, 2008.

Sinha, M. P.: Laser induced volatilization and ionization of microparticles, Rev. Sci. Instrum., 55, 886-891, 1984.

Sinha, M. P., Giffin, C. E., Norris, D. D., Estes, T. J., Vilker, V. L., and Friedlander, S. K.: Particle Analysis by Mass-Spectrometry, J. Colloid Interf. Sci., 87, 140-153, 1982.

Smith, G. D., Woods, E., DeForest, C. L., Baer, T., and Miller, R. E.: Reactive uptake of ozone by oleic acid aerosol particles: Application of single-particle mass spectrometry to heterogeneous reaction kinetics, J. Phys. Chem., 106, 8085-8095, 2002.

Su, Y., Sipin, M. F., Furutani, H., and Prather, K. A.: Development and Characterization of an Aerosol Time-of-Flight Mass Spectrometer with Increased Detection Efficiency, Anal. Chem., 76, 712-719, 2004.

Suess, D. T. and Prather, K. A.: Mass spectrometry of aerosols, Chem. Rev., 99, 3007-3035, 1999.

Sullivan, R. C. and Prather, K. A.: Recent Advances in Our Understanding of Atmospheric Chemistry and Climate Made Possible by On-Line Aerosol Analysis Instrumentation, Anal. Chem., 77, 3861-3886, 2005.

Sykes, D. C., Woods III, E., Smith, G. D., Baer, T., and Miller, R. E.: Thermal vaporization-vacuum Ultraviolet Laser Ionization Time-of-Flight Mass Spectrometry, Anal. Chem., 74, 2048-2052, 2002.

Tobias, H. J. and Ziemann, P. J.: Compound Identification in Organic Aerosols Using Temperature- Programmed Thermal Desorption Particle Beam Mass Spectrometry, Anal. Chem., 71, 3428-3435, 1999.

Tobias, H. J., Kooiman, P. M., Docherty, K. S., and Ziemann, P. J.: Real-Time Chemical Analysis of Organic Aerosols Using a Thermal Desorption Particle Beam Mass Spectrometer, Aerosol Sci. Tech., 33, 170-190, 2000.

Tsigaridis, K. and Kanakidou, M.: Global modelling of secondary organic aerosol in the troposphere: a sensitivity analysis, Atmos. Chem. Phys., 3, 1849-1869, doi:10.5194/acp-3-1849-2003, 2003.

Vedal, S. and Dutton, S. J.: Wildfire air pollution and daily mortality in a large urban area, Environ. Res., 102, 29-35, 2006.
Wang, J., Doussin, J. F., Perrier, S., Perraudin, E., Katrib, Y., Pangui, E., and Picquet-Varrault, B.: Design of a new multi-phase experimental simulation chamber for atmospheric photosmog, aerosol and cloud chemistry research, Atmos. Meas. Tech., 4, 2465-2494, doi:10.5194/amt-4-2465-2011, 2011.

Wang, X., and McMurry, P. H.: A Design Tool for Aerodynamic Lens Systems, Aerosol Sci. Tech. 40, 320-334, 2006.

Wang, X., Kruis, F. E., and McMurry, P. H.: Aerodynamic focusing of nanoparticles: I. Guidelines for Designing aerodynamic lenses for nanoparticles, Aerosol Sci. Tech., 39, 611-623, 2005a.

Wang, X., Gidwani, A., Girshick, S. L., and McMurry, P. H.: Aerodynamic focusing of nanoparticles: II. Numerical simulation of particle motion through aerodynamic lenses, Aerosol Sci. Tech., 39, 624-636, 2005b.

Weiss, M., Verheijen, P. J. T., Marijnissen, J. C. M., and Scarlett, B.: On the performance of an on-line time-of-flight mass spectrometer for aerosols, J. Aerosol Sci., 28, 159-171, 1997.

Wilson, K. R., Jimenez-Cruz, M., Nicolas, C., Belau, L., Leone, S. R., and Ahmed, M.: Thermal Vaporization of Biological Nanoparticles: Fragment-Free Vacuum Ultraviolet Photoionization Mass Spectra of Tryptophan, Phenylalanine Glycine Glycine, and $\beta$-Carotene, J. Phys. Chem. A, 110, 2106-2113, 2006.

Woods, E., Smith, G. D., Dessiaterik, Y., Baer, T., and Miller, R. E.: Quantitative detection of aromatic compounds in single particle mass spectrometry, Anal. Chem., 73, 2317-2322, 2001.

Wiley, W. C. and McLaren, I. H.: Time-of-Flight mass spectrometer with improved resolution, Rev. Sci. Instrum., 26, 1150-1157, 1955.

Zelenyuk, A. and Imre, D.: Single Particle Laser Ablation Time-ofFlight Mass Spectrometer: An Introduction to SPLAT, Aerosol Sci. Tech., 39, 554-568, 2005.

Zhang, Q., Jimenez, J. L., Canagaratna, M. R., Allan, J. D., Coe, H., Ulbrich, I., Alfarra, M. R., Takami, A., Middelbrook, A. M., Sun, Y. L., Dezpina, K., Dunlea, E., Docherty, K., Decarlo, P. F., Salcedo, D., Onasch, T., Jayne, J. T., Miyoshi, T., Shimono, A., Hatakeyama, S., Takegawa, N., Kondo, Y., Schneider, J., Drewnick, F., Borrmann, S., Weimer, S., Demerjian, K., Williams, P., Bower, K., Bahreini, R., Cottrelli, L., Griffin, R., Ruatiainen, J., Sun, J. Y., Zhang, Y. M., and Worsnop, D. R.: Ubiquity and dominance of oxygenated species in organic aerosols in anthropogenically influenced Northern Hemisphere midlatitudes, Geophys. Res. Lett., 34, L13801, doi:10.1029/2007GL029979, 2007.

Zimmermann, R., Heger, H. J., Kettrup, A., and Boesl, U.: A mobile resonance laser ionization time-of-flight mass spectrometry - Device for on-line analysis of aromatic pollutants in waste incinerator flue gases, Rapid Commun. Mass Sp., 11, 1095-1102, 1997. 